\title{
cis-Diastereoselective Synthesis of Spirooxindolo- $\beta$-Lactams by Staudinger Cycloaddition with TsCl as Activating Co-reagent
}

Vadim E. Filatov, Juliana Kuznetsova, Lada Petrovskaya, Dmitry Yuzabchuk, Victor A. Tafeenko, Nikolay V. Zyk, and Elena K. Beloglazkina*

Department of Chemistry, Lomonosov Moscow State University,Leninskie gory 1/3, 119991 Moscow, Russian Federation.

*Email: beloglazki@mail.ru; bel@org.chem.msu.ru

Vadim E. Filatov - Department of Chemistry, Lomonosov Moscow State University,Leninskie gory 1/3, 119991 Moscow, Russian Federation; Email: NanoVF@mail.ru

Juliana Kusnetsova - Department of Chemistry, Lomonosov Moscow State University,Leninskie gory 1/3, 119991 Moscow, Russian Federation; Email: ulenkaiulenka@mail.ru

Lada Petrovskaya - Department of Chemistry, Lomonosov Moscow State University,Leninskie gory 1/3, 119991 Moscow, Russian Federation; Email: petrovskayalada@mail.ru

Dmitry Yusabchuk - Department of Chemistry, Lomonosov Moscow State University,Leninskie gory 1/3, 119991 Moscow, Russian Federation; Email: dmitry.yuzabchuk@gmail.com

Victor A. Tafeenko - Department of Chemistry, Lomonosov Moscow State University,Leninskie gory 1/3, 119991 Moscow, Russian Federation; Email: tafeenko-victor@yandex.ru

Nikolay V. Zyk-Department of Chemistry, Lomonosov Moscow State University,Leninskie gory 1/3, 119991 Moscow,Russian Federation; Email: zyk@org.chem.msu.ru

\section{Supporting Information}

\section{Table of contents}

Spectral data. .53

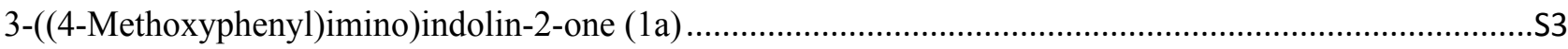

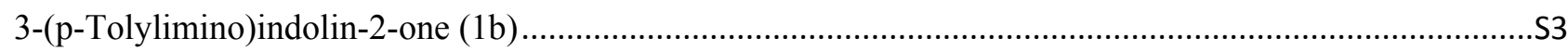

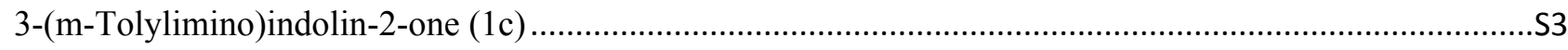

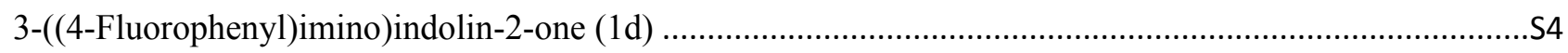

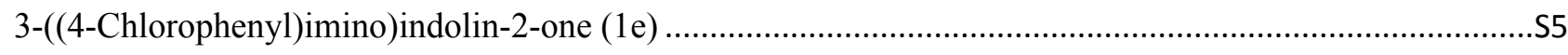

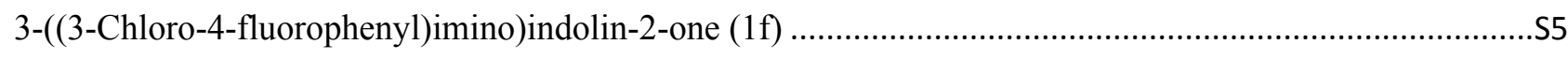

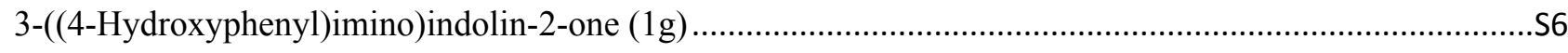

(2R*,3 $\left.\mathrm{S}^{*}\right)$-3-(4-Ffluorophenyl)-1-(4-methoxyphenyl)spiro[azetidine-2,3'-indoline]-2',4-dione (cis-3a)........S7

(2R*,3 $\left.\mathrm{S}^{*}\right)$-3-(4-Chlorophenyl)-1-(4-methoxyphenyl)spiro[azetidine-2,3'-indoline]-2',4-dione (cis-3b).........S9

(2R*,3R*)-3-(4-Chlorophenyl)-1-(4-methoxyphenyl)spiro[azetidine-2,3'-indoline]-2',4-dione (trans-3b)...S11

$\left(2 \mathrm{R}^{*}, 3 \mathrm{~S}^{*}\right)-3-(4-$ Bromophenyl)-1-(4-methoxyphenyl)spiro[azetidine-2,3'-indoline]-2',4-dione (cis-3c).......S13

(2R*,3R*)-3-(4-Bromophenyl)-1-(4-methoxyphenyl)spiro[azetidine-2,3'-indoline]-2',4-dione (trans-3c) ...S15 
(2R*,3 $\left.\mathrm{S}^{*}\right)$-3-(3,4-Dichlorophenyl)-1-(4-methoxyphenyl)spiro[azetidine-2,3'-indoline]-2',4-dione (cis-3d) S17

(2R*,3S*)-3-(4-Chlorophenyl)-1-(p-tolyl)spiro[azetidine-2,3'-indoline]-2',4-dione (cis-3e) ......................S19

(2*R,3S*)-3-(4-Bromophenyl)-1-(p-tolyl)spiro[azetidine-2,3'-indoline]-2',4-dione (cis-3f).......................S21

(2R*,3S*)-3-(3,4-Difluorophenyl)-1-(p-tolyl)spiro[azetidine-2,3'-indoline]-2',4-dione (cis-3g) .................S23

(2R*,3S*)-3-(4-Chlorophenyl)-1-(m-tolyl)spiro[azetidine-2,3'-indoline]-2',4-dione (cis-3h).....................S25

$\left(2 \mathrm{R}^{*}, 3 \mathrm{~S}^{*}\right)-1,3$-bis(4-Chlorophenyl)spiro[azetidine-2,3'-indoline]-2',4-dione (cis-3i) .................................S27

$\left(2 \mathrm{R}^{*}, 3 \mathrm{~S}^{*}\right)-3-(4-B r o m o p h e n y l)-1-(4-$ chlorophenyl)spiro[azetidine-2,3'-indoline]-2',4-dione (cis-3j) ...........S29

(2R*,3S*)-3-(4-Bromophenyl)-1-(3-chloro-4-fluorophenyl)spiro[azetidine-2,3'-indoline]-2',4-dione (cis-3k)

(2R*,3R*)-3-(4-Bromophenyl)-1-(3-chloro-4-fluorophenyl)spiro[azetidine-2,3'-indoline]-2',4-dione (trans-

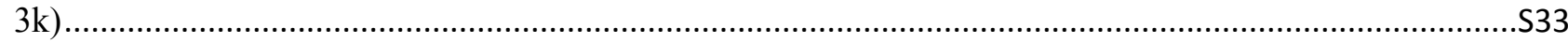

(2R*,3S*)-3-(4-Chlorophenyl)-1-(4-hydroxyphenyl)spiro[azetidine-2,3'-indoline]-2',4-dione (cis-31) ........S35

(2R*,3R*)-3-(4-Chlorophenyl)-1-(4-hydroxyphenyl)spiro[azetidine-2,3'-indoline]-2',4-dione (trans-31) ....S37

$\left(2 \mathrm{R}^{*}, 3 \mathrm{~S}^{*}\right)$-1,3-bis(4-Methoxyphenyl)spiro[azetidine-2,3'-indoline]-2',4-dione (cis-3m) ............................S39

(2R*,3R*)-1,3-bis(4-Methoxyphenyl)spiro[azetidine-2,3'-indoline]-2',4-dione (trans-3m) ........................S41

(2R*,3R*)-1-(4-Fluorophenyl)-3-(4-methoxyphenyl)spiro[azetidine-2,3'-indoline]-2',4-dione (trans-3n) ...S43

(2R*,3S*)-1-(3-Chloro-4-fluorophenyl)-3-(4-methoxyphenyl)spiro[azetidine-2,3'-indoline]-2',4-dione (cis-

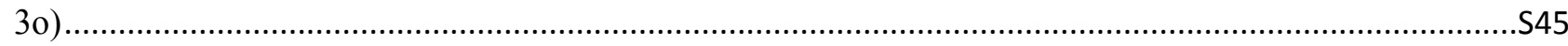

(2R*,3R*)-1-(3-Chloro-4-fluorophenyl)-3-(4-methoxyphenyl)spiro[azetidine-2,3'-indoline]-2',4-dione (trans$30)$.

(2R*,3R*)-1-(4-Hydroxyphenyl)-3-(4-methoxyphenyl)spiro[azetidine-2,3'-indoline]-2',4-dione (trans-3p)S49 X-Ray .551

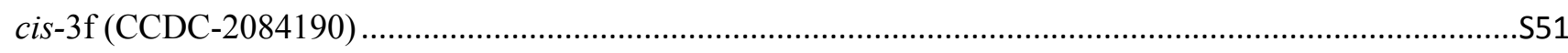

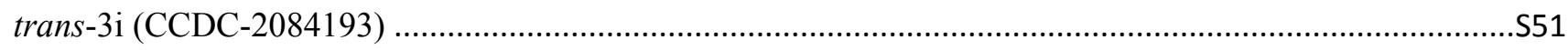

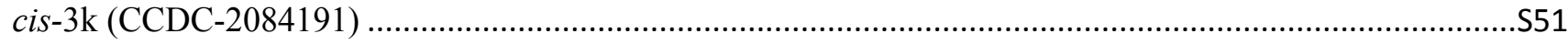




\section{Spectral data}

\section{3-((4-Methoxyphenyl)imino)indolin-2-one (1a)}

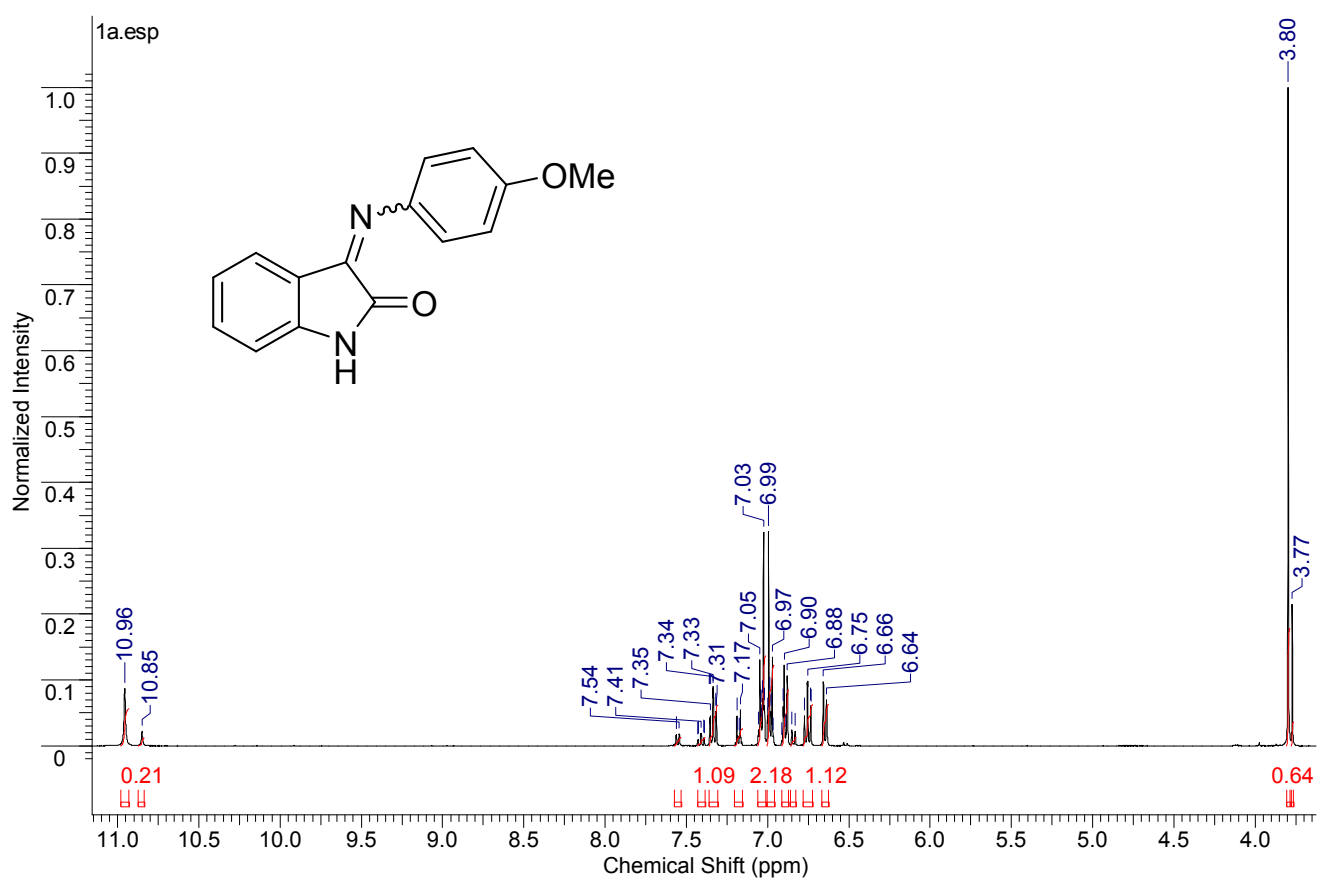

Figure S1. ${ }^{1} \mathrm{H}$ NMR spectrum of compound 1a

\section{3-(p-Tolylimino)indolin-2-one (1b)}

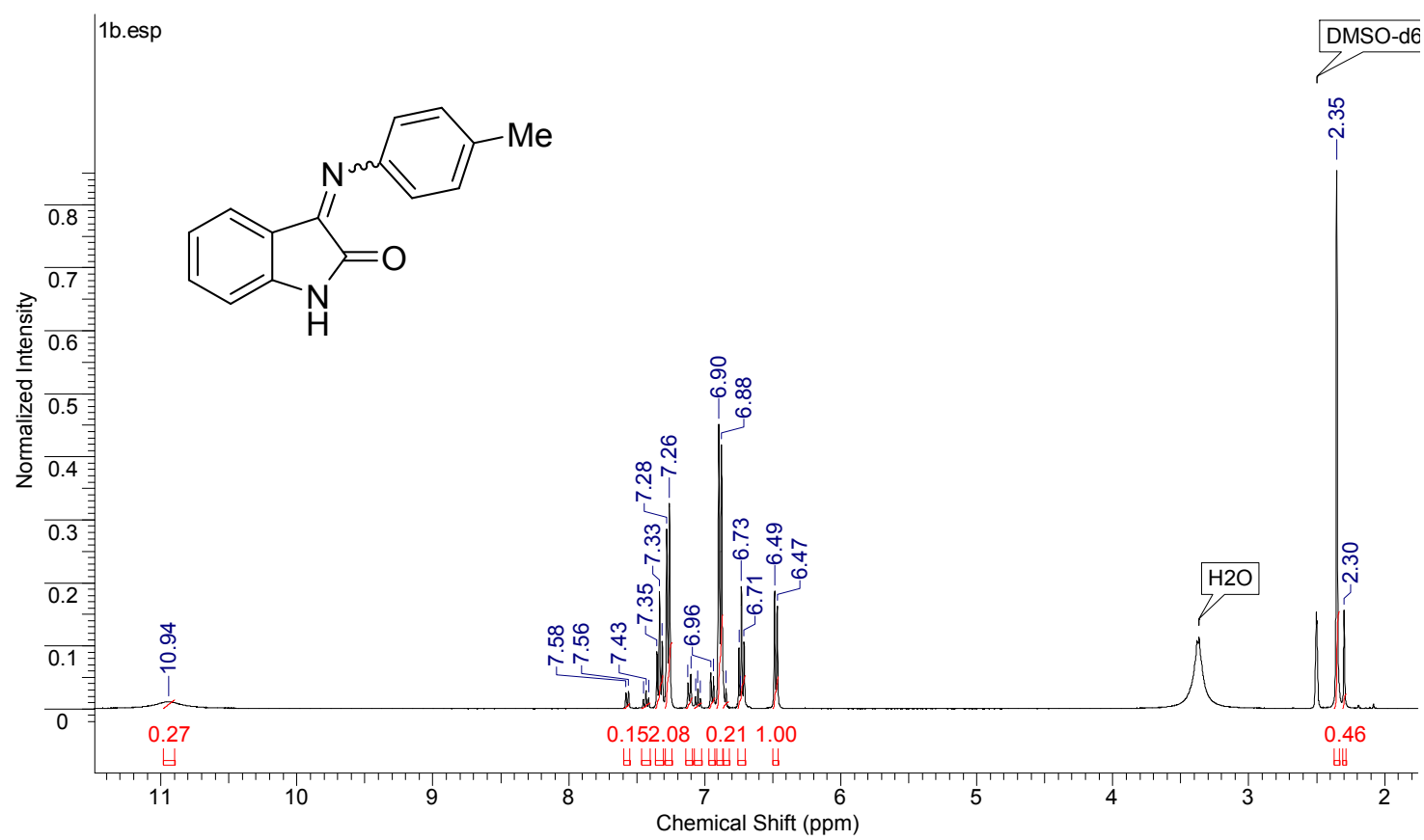

Figure S2. ${ }^{1} \mathrm{H}$ NMR spectrum of compound $\mathbf{1 b}$ 


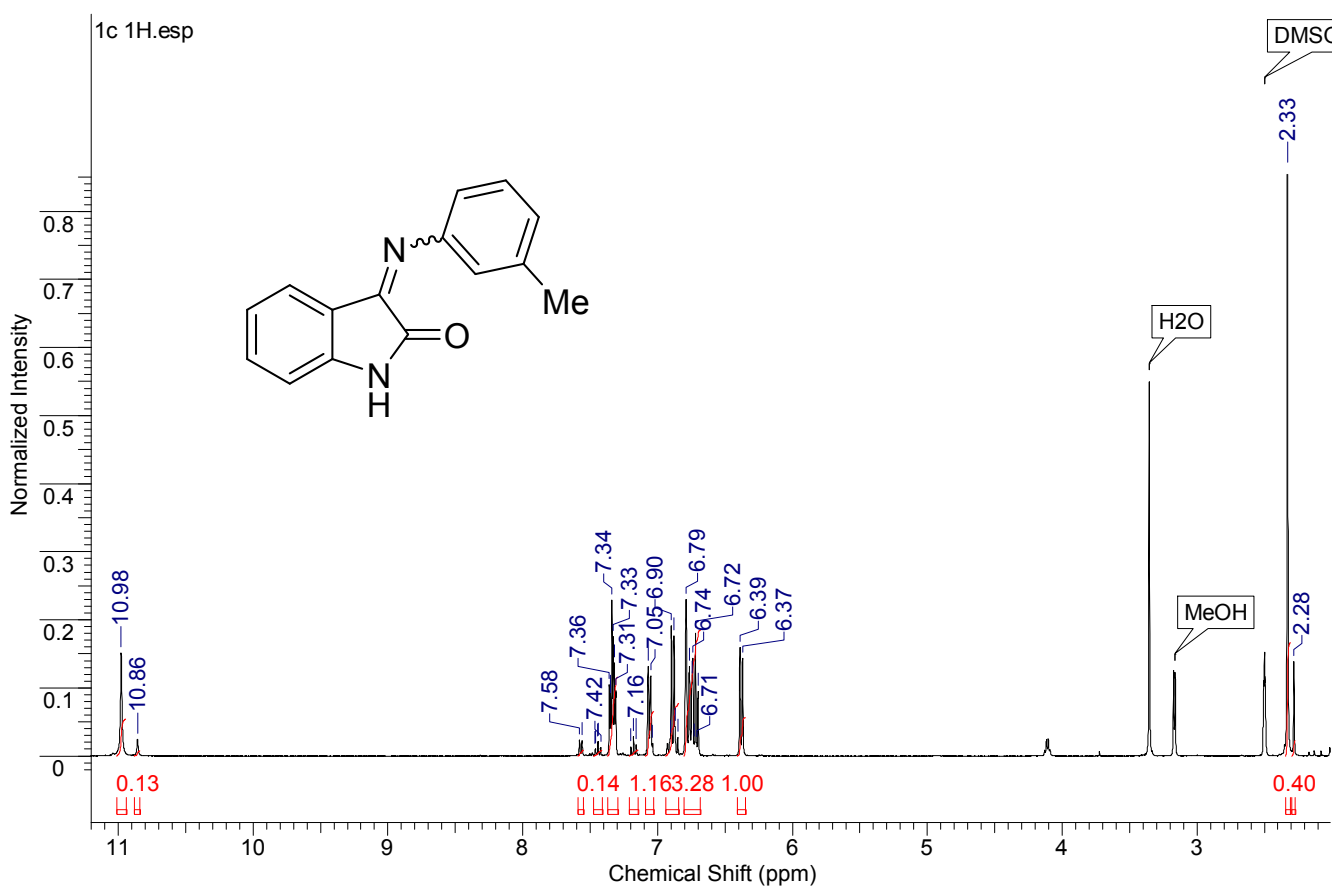

Figure S3. ${ }^{1} \mathrm{H}$ NMR spectrum of compound 1c

\section{3-((4-Fluorophenyl)imino)indolin-2-one (1d)}

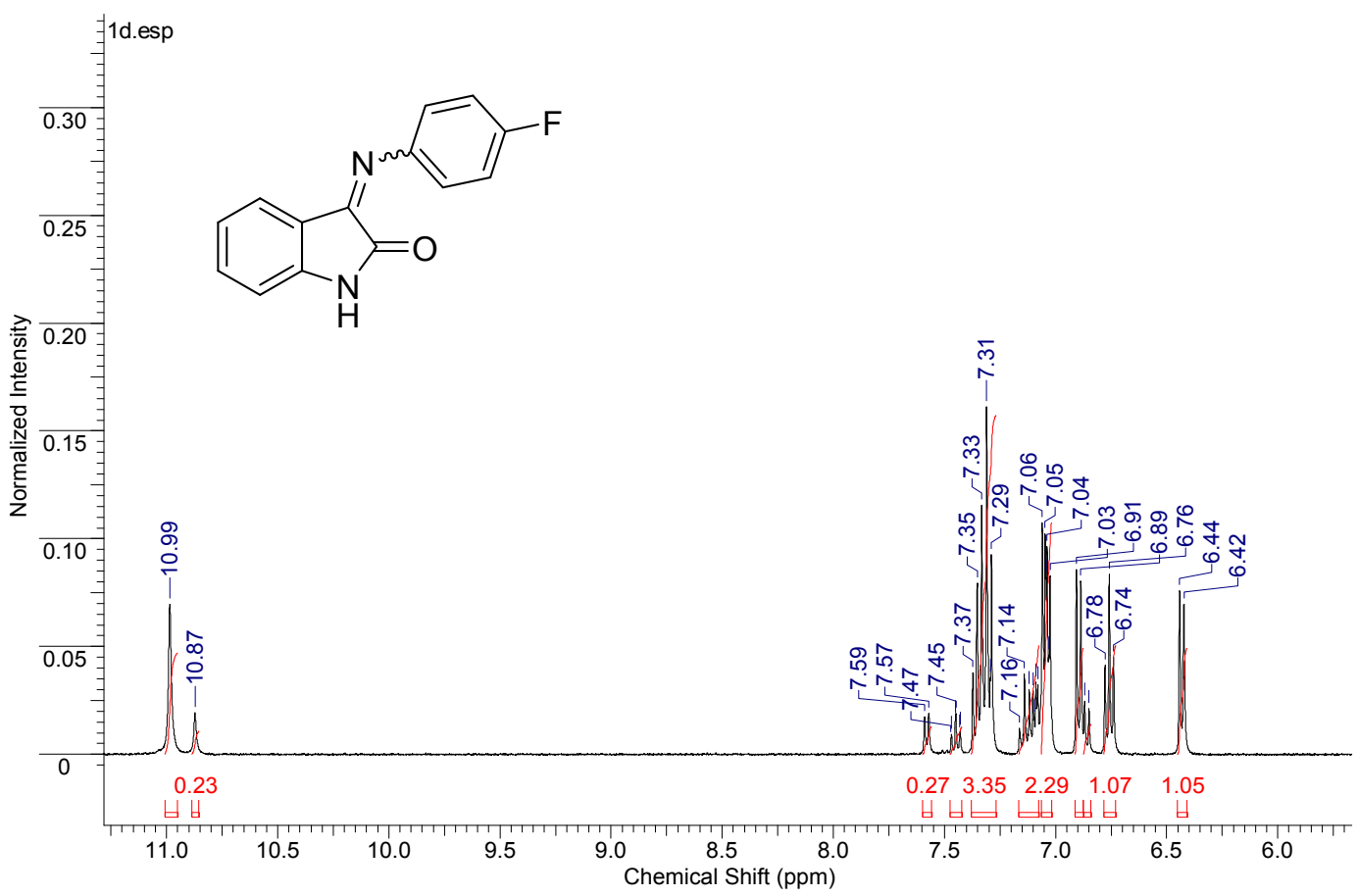

Figure S4. ${ }^{1} \mathrm{H}$ NMR spectrum of compound 1d 


\section{3-((4-Chlorophenyl)imino)indolin-2-one (1e)}

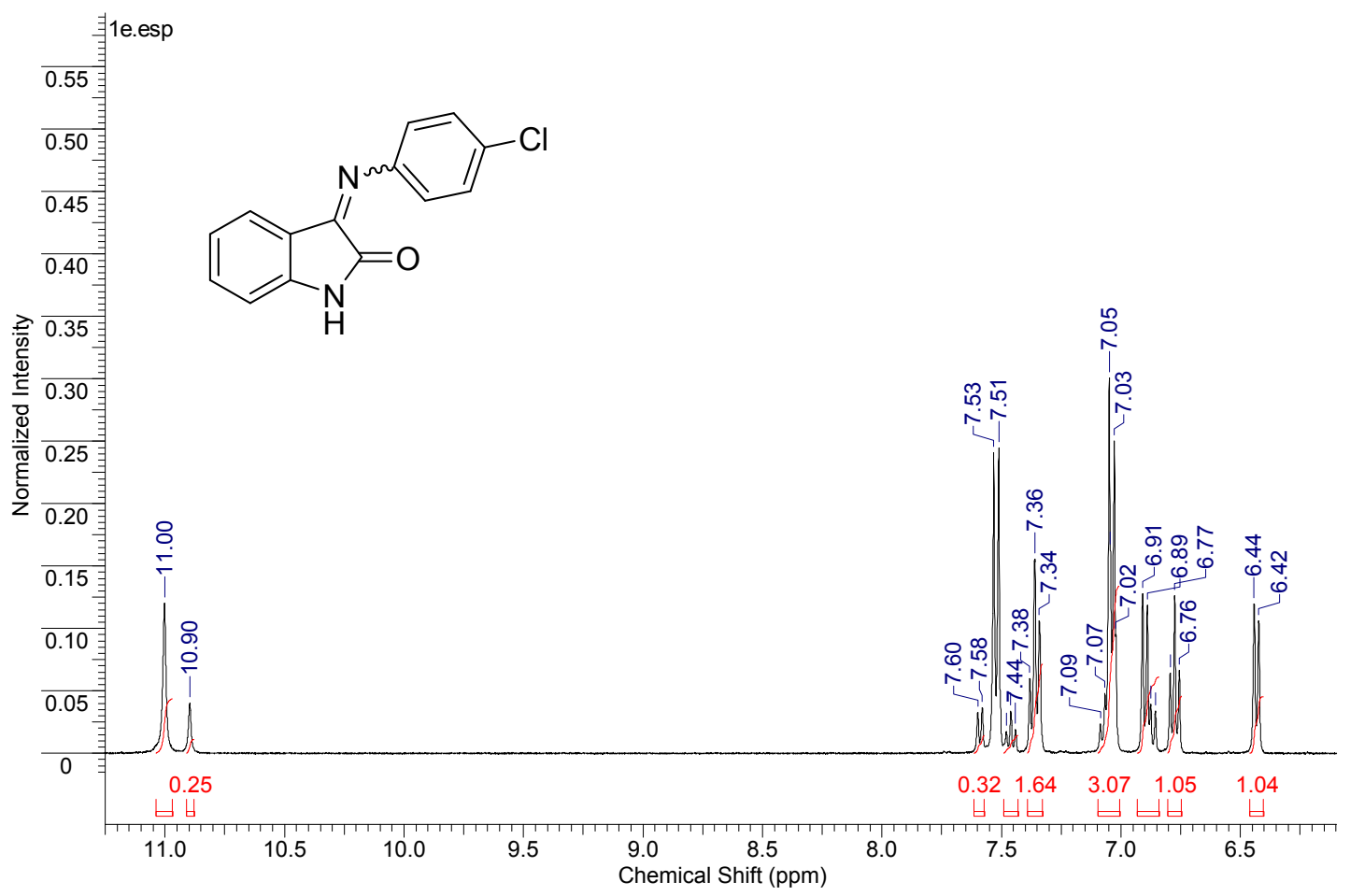

Figure S5. ${ }^{1} \mathrm{H}$ NMR spectrum of compound 1e

\section{3-((3-Chloro-4-fluorophenyl)imino)indolin-2-one (1f)}

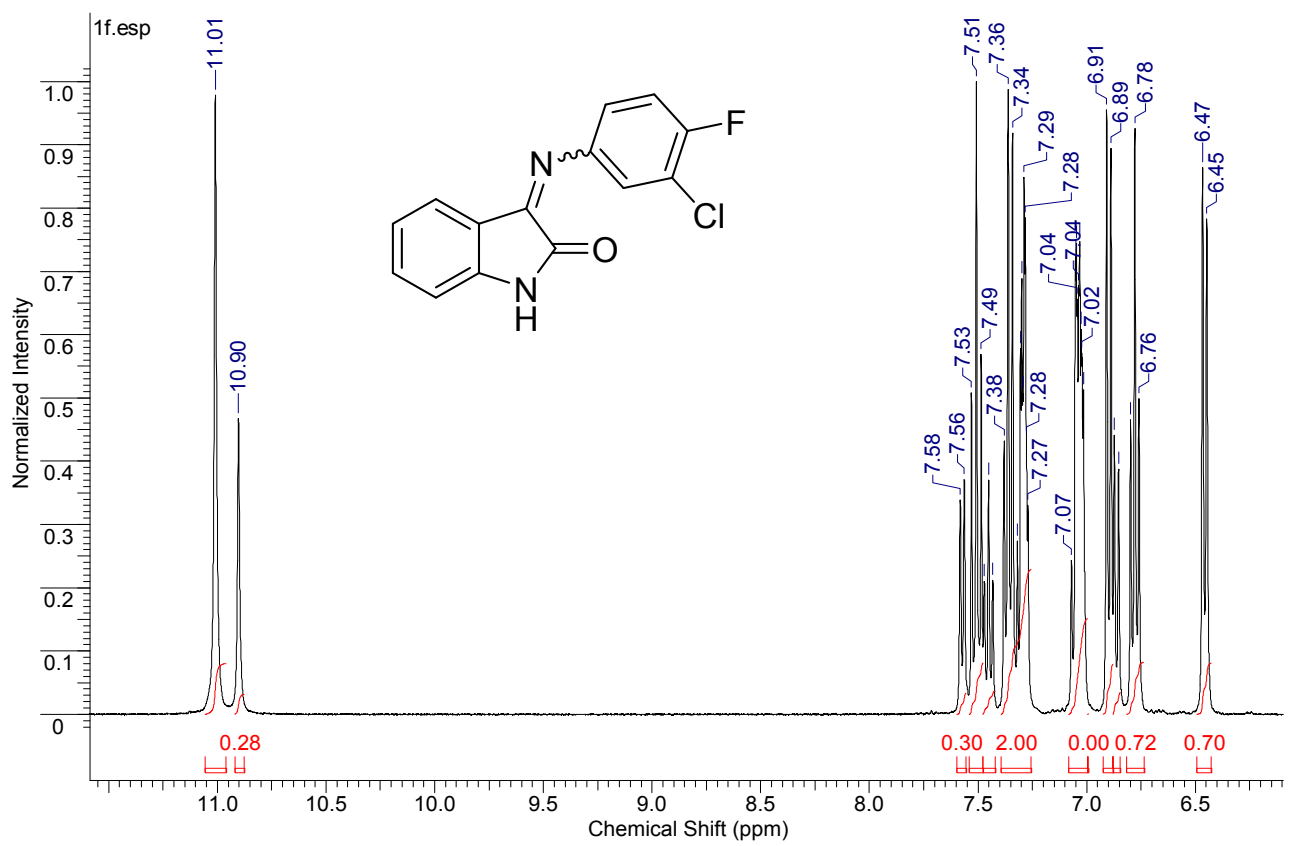

Figure S6. ${ }^{1} \mathrm{H}$ NMR spectrum of compound $\mathbf{1 f}$ 


\section{3-((4-Hydroxyphenyl)imino)indolin-2-one (1g)}

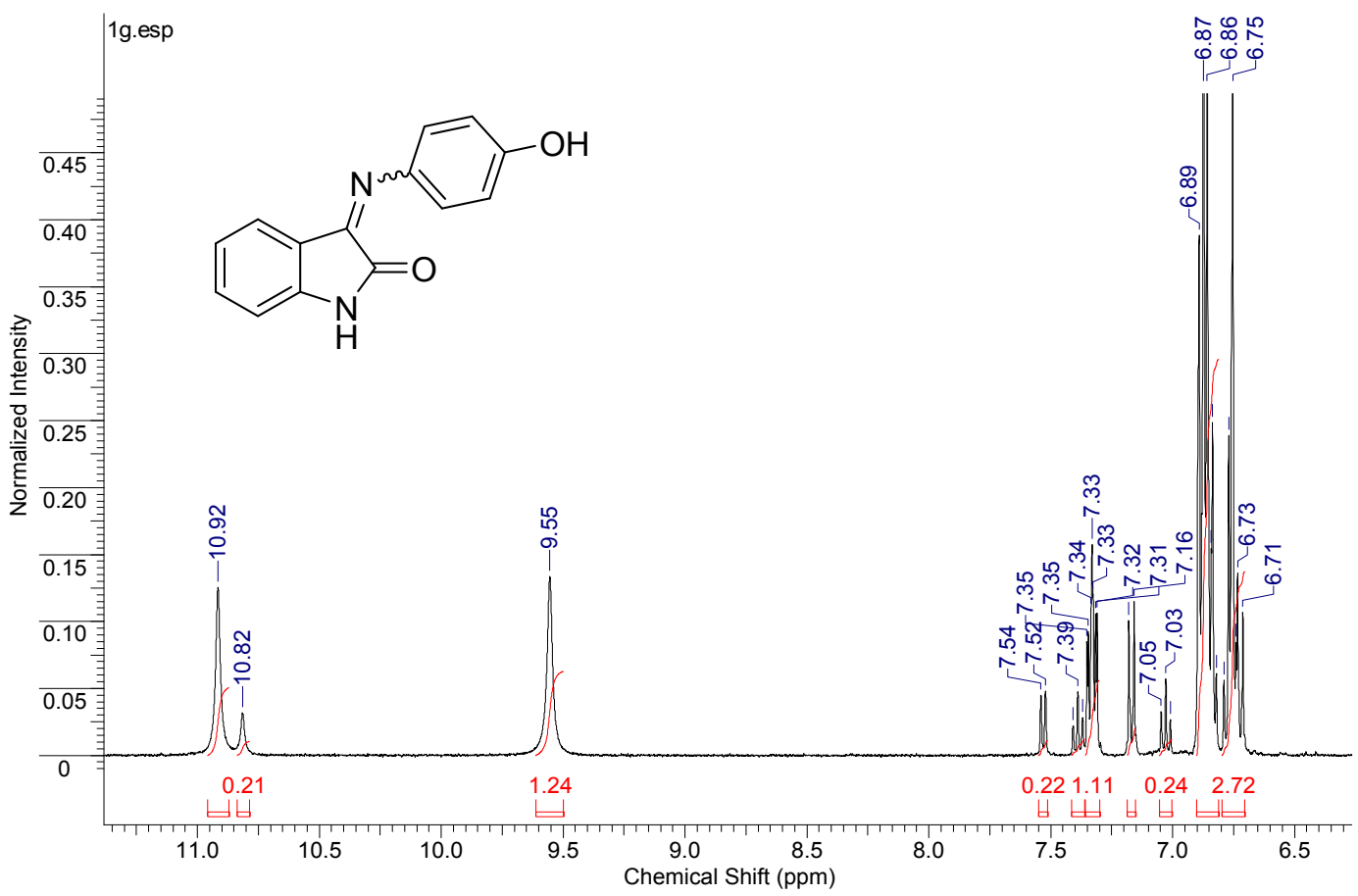

Figure S7. ${ }^{1} \mathrm{H}$ NMR spectrum of compound $\mathbf{1 g}$ 
(cis-3a)
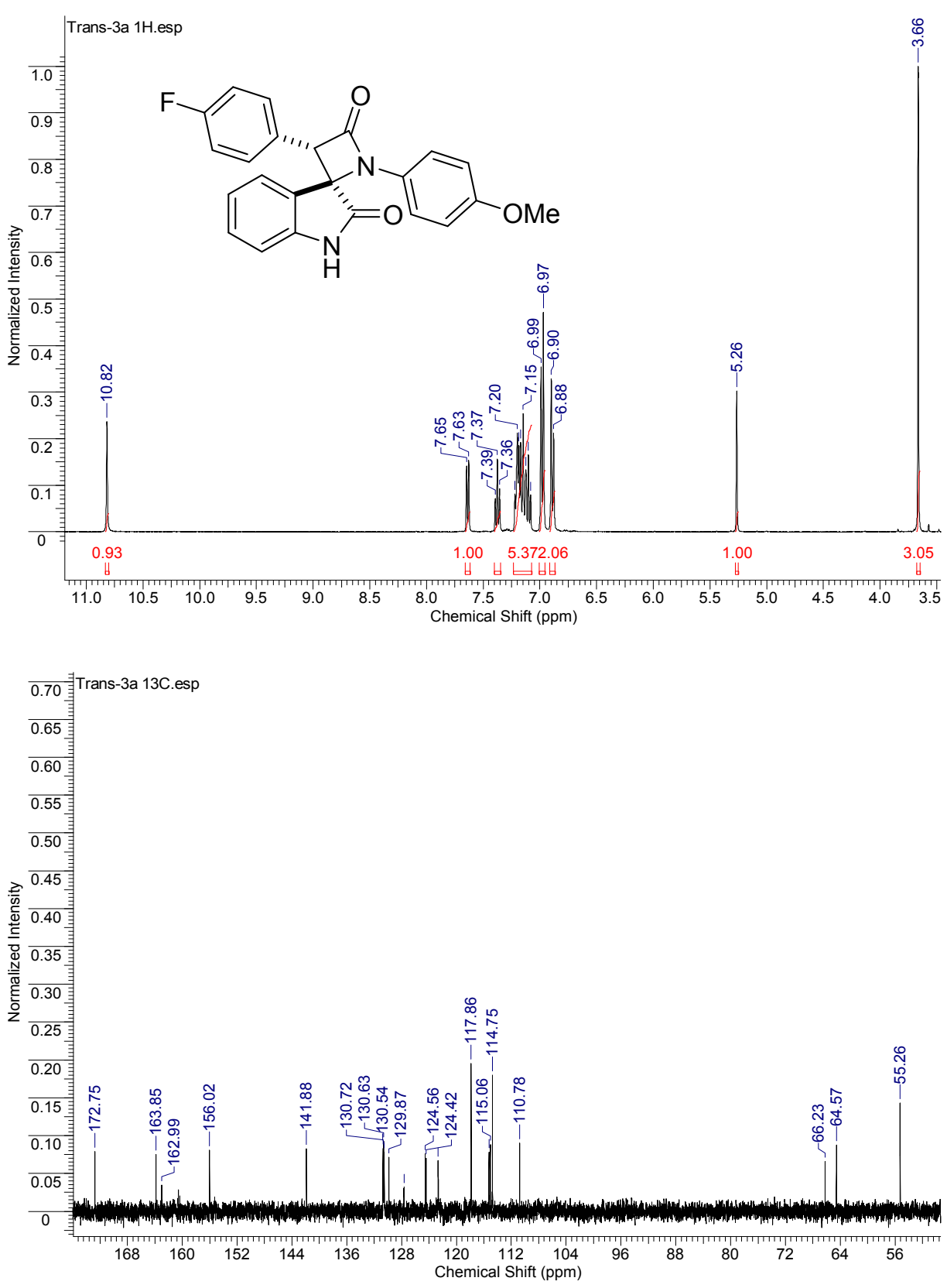

Figure S8. ${ }^{1} \mathrm{H}$ and ${ }^{13} \mathrm{C}$ NMR spectra of compound cis-3a 


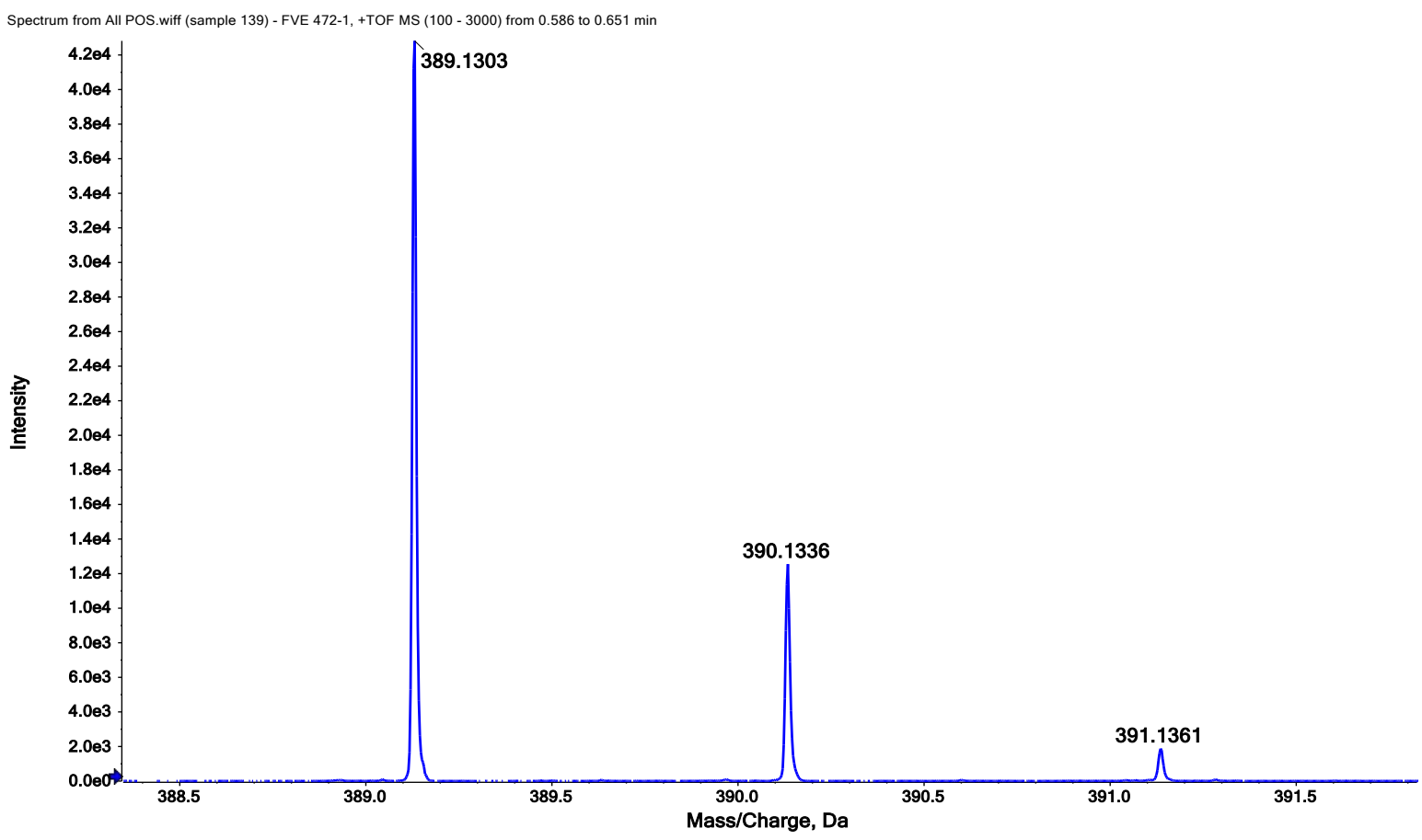

Figure S9. HRMS spectrum of compound cis-3a 
$\underline{(\text { cis-3b) }}$
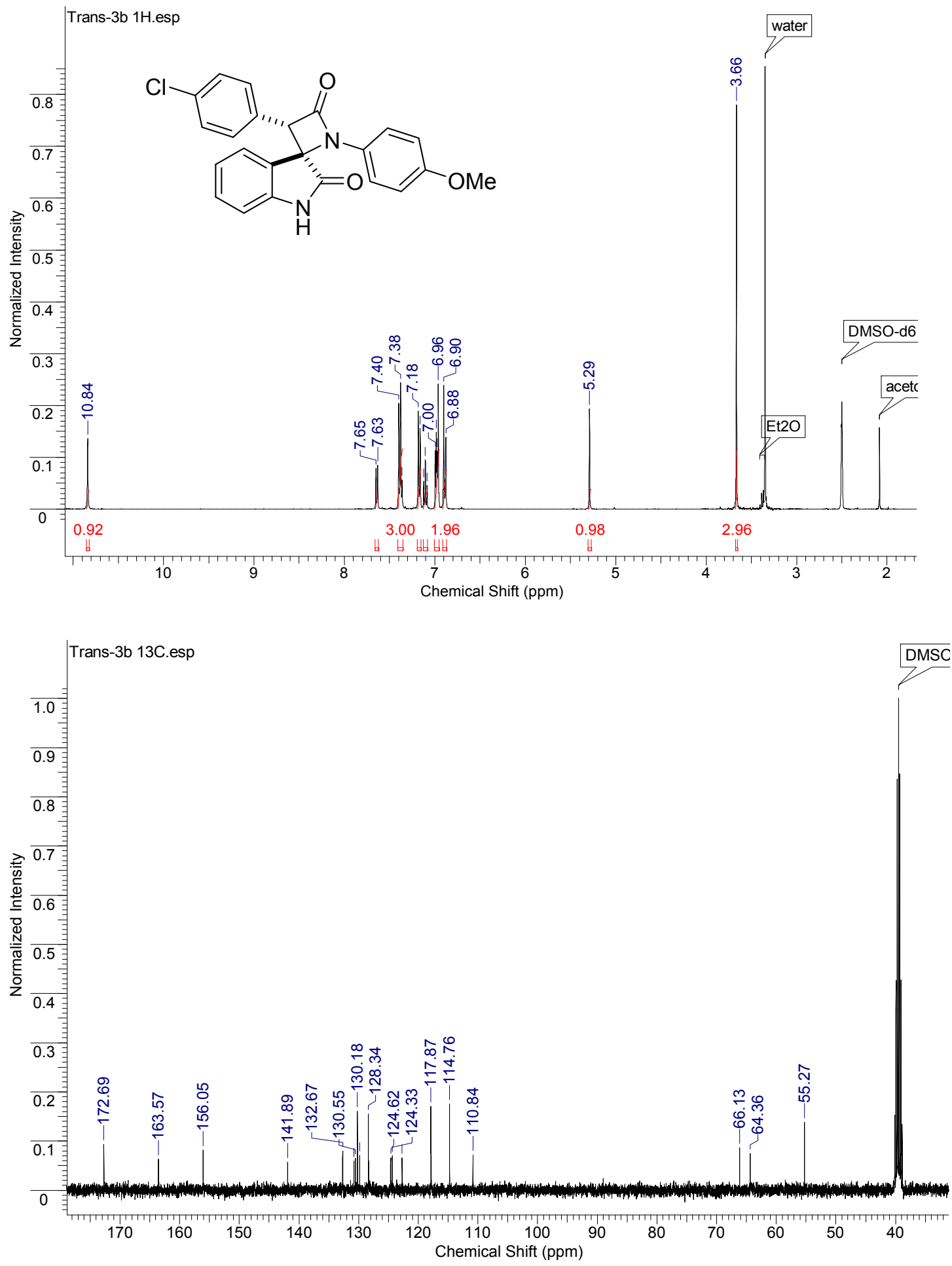

Figure S10. ${ }^{1} \mathrm{H}$ and ${ }^{13} \mathrm{C}$ NMR spectra of compound cis-3b 


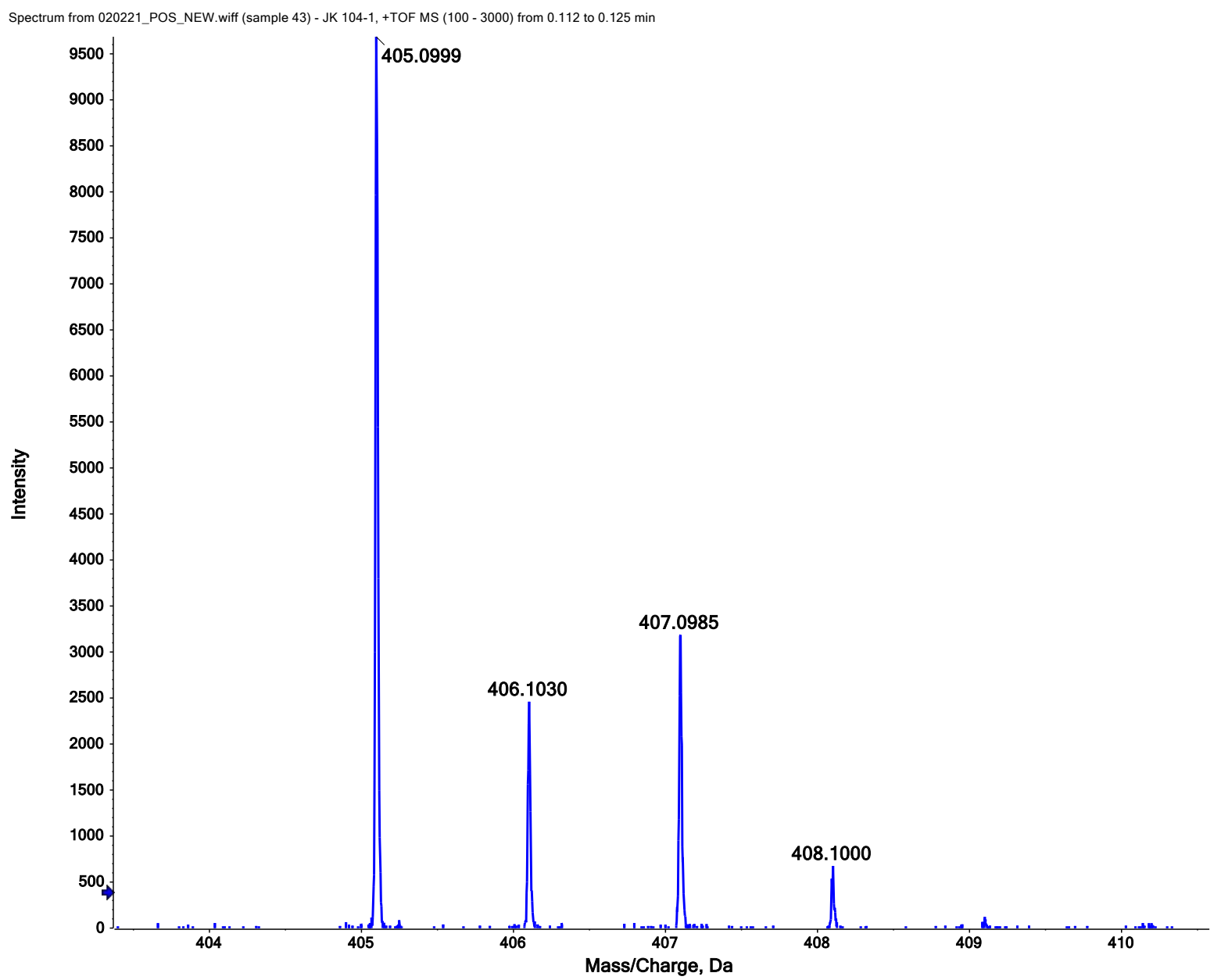

Figure S11. HRMS spectrum of compound cis-3b 
$\underline{(\text { trans-3b) }}$
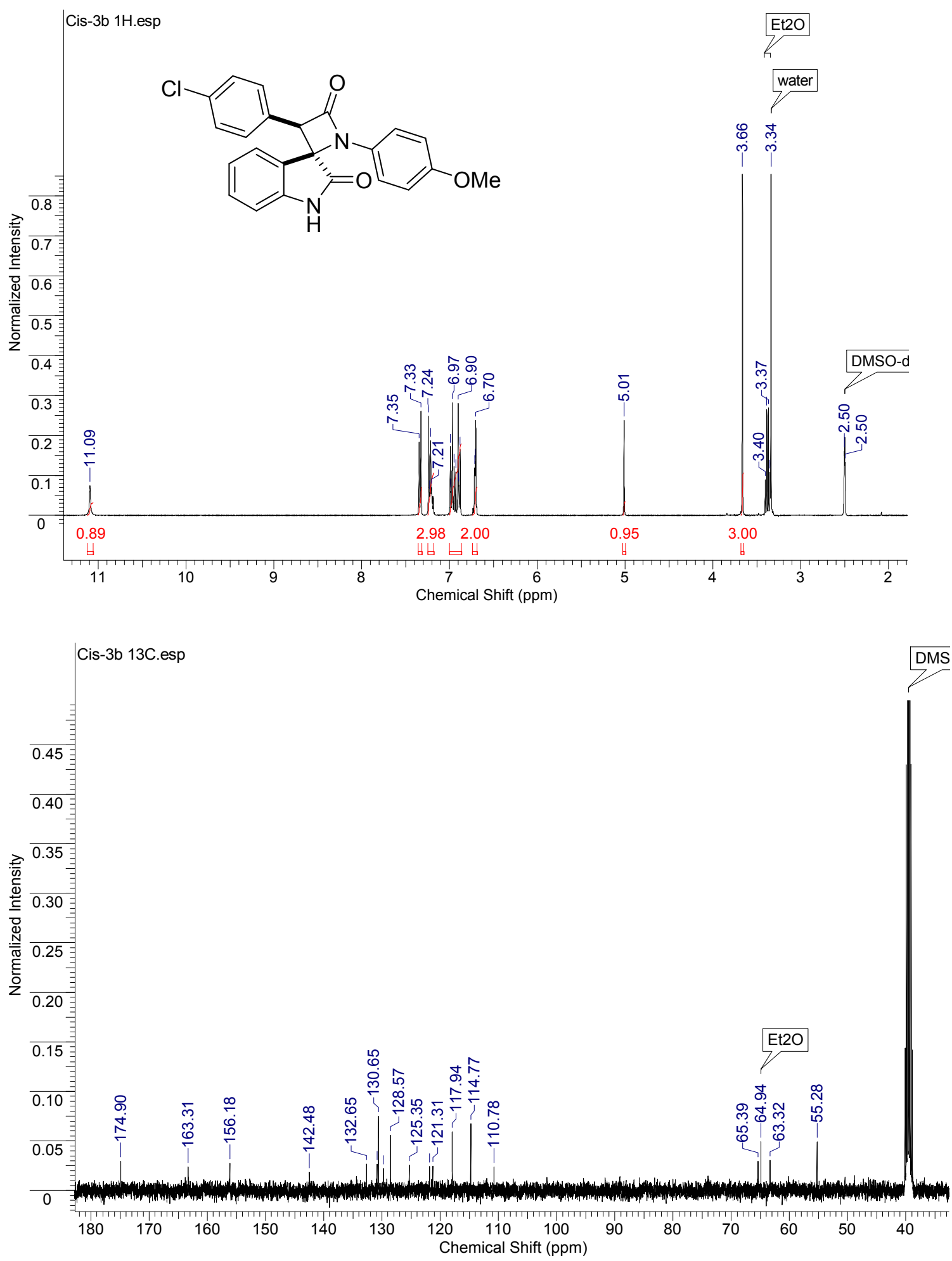

Figure $\mathrm{S} 12 .{ }^{1} \mathrm{H}$ and ${ }^{13} \mathrm{C}$ NMR spectra of compound trans-3b 


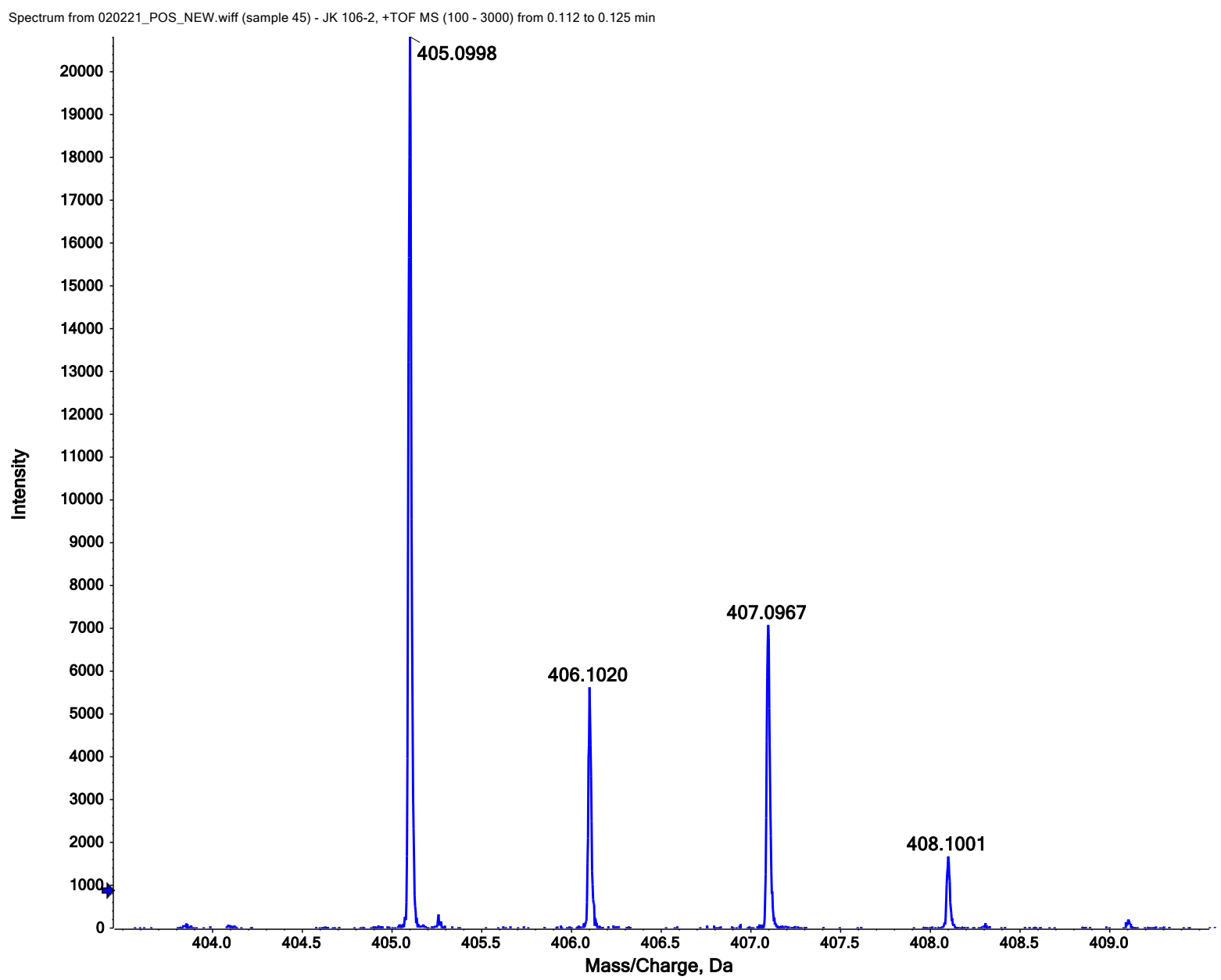

Figure S13. HRMS spectrum of compound trans-3b 
$\underline{(\text { cis-3c) }}$
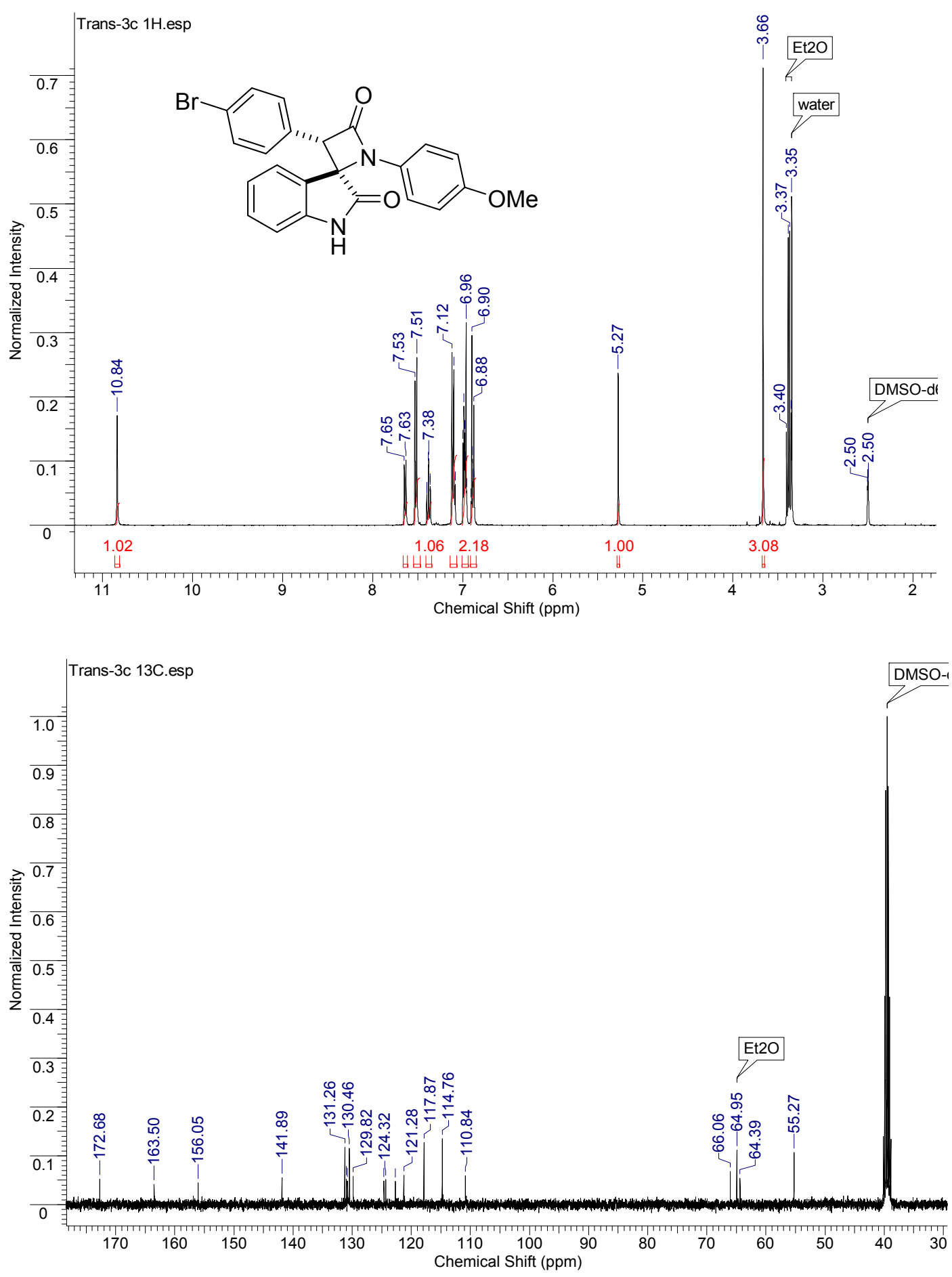

Figure S14. ${ }^{1} \mathrm{H}$ and ${ }^{13} \mathrm{C}$ NMR spectra of compound cis-3c 


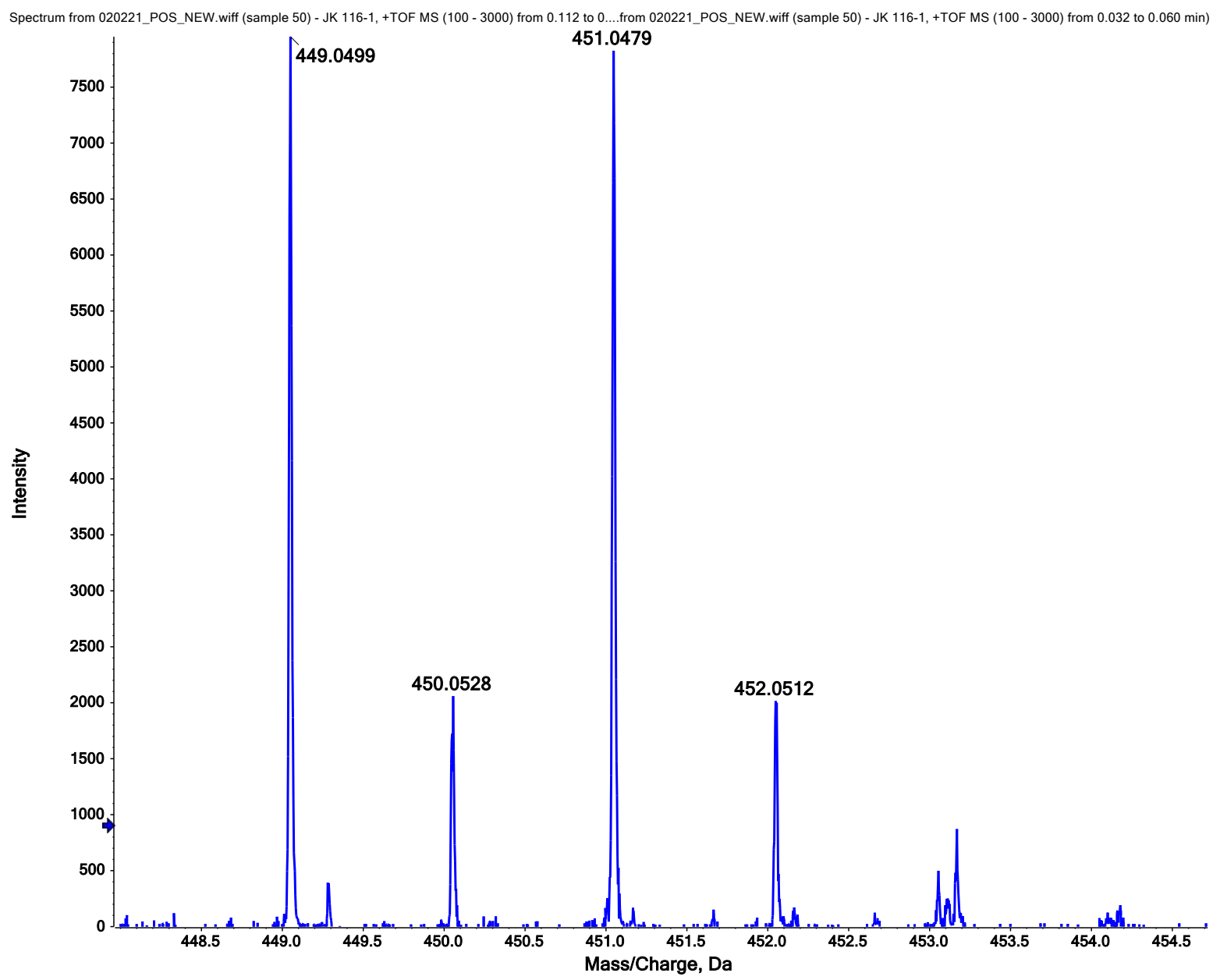

Figure S15. HRMS spectrum of compound cis-3c 
$\underline{(\text { trans-3c) }}$
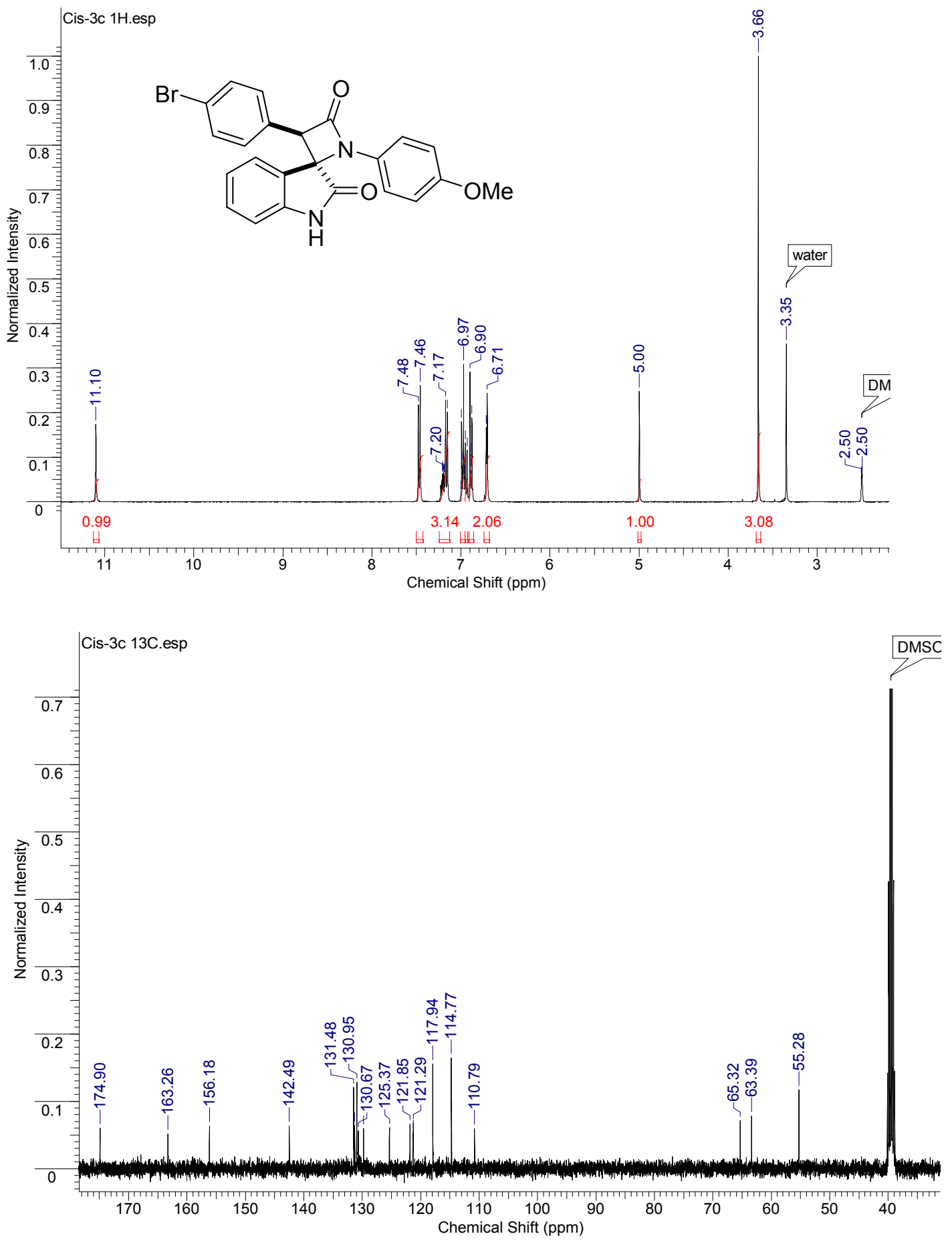

Figure S16. ${ }^{1} \mathrm{H}$ and ${ }^{13} \mathrm{C}$ NMR spectra of compound trans-3c 
Spectrum from 050321_POS.wiff (sample 49) - JK 149 2, +TOF MS (100 - 3000) from 0.098...050321_POS. wiff (sample 49) - JK 149 2, +TOF MS (100 - 3000$)$ from 0.032 to 0.065 min)

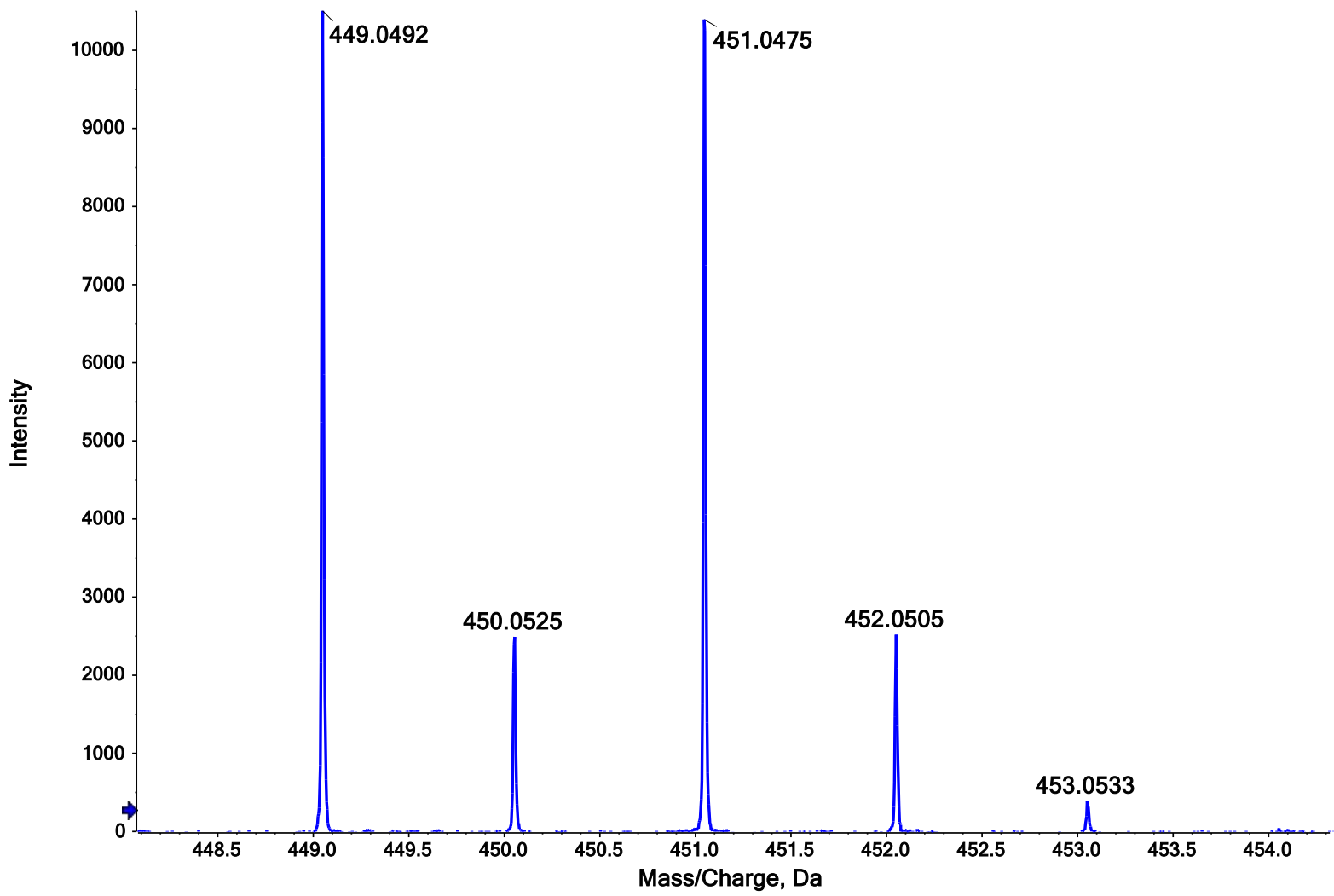

Figure S17. HRMS spectrum of compound trans-3c 

dione (cis-3d)
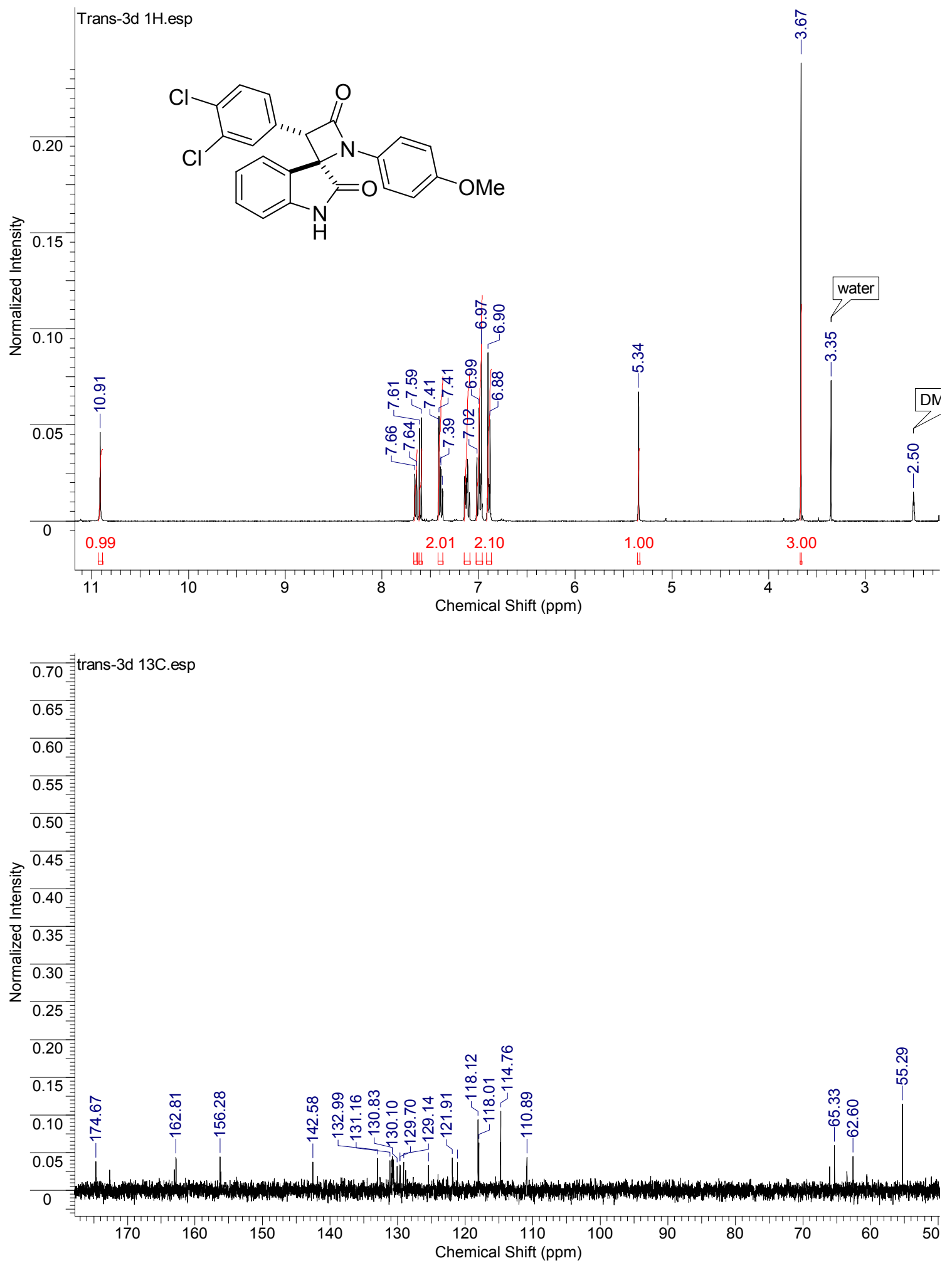

Figure $\mathrm{S} 18 .{ }^{1} \mathrm{H}$ and ${ }^{13} \mathrm{C}$ NMR spectra of compound cis-3d 


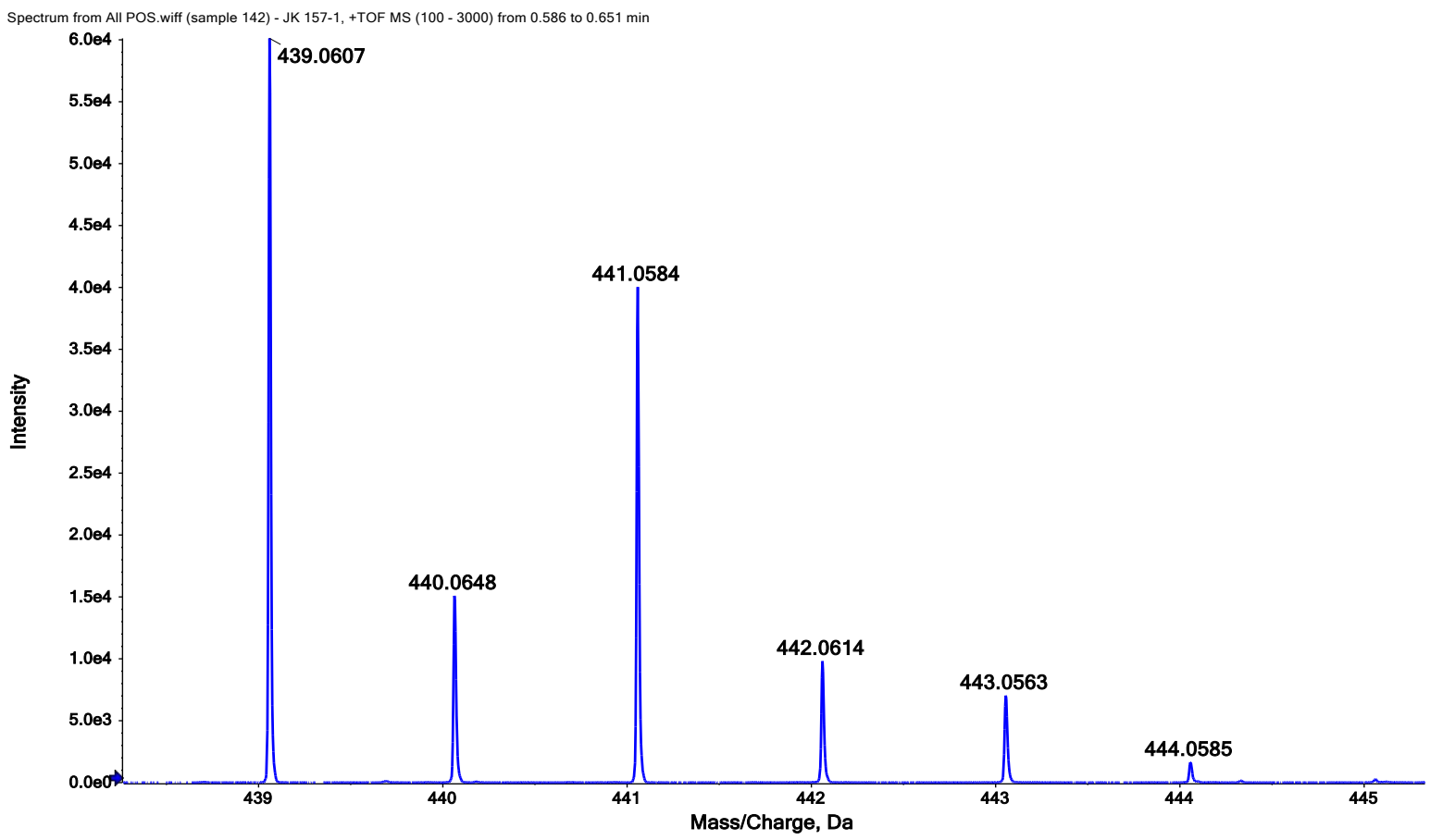

Figure S19. HRMS spectrum of compound cis-3d 

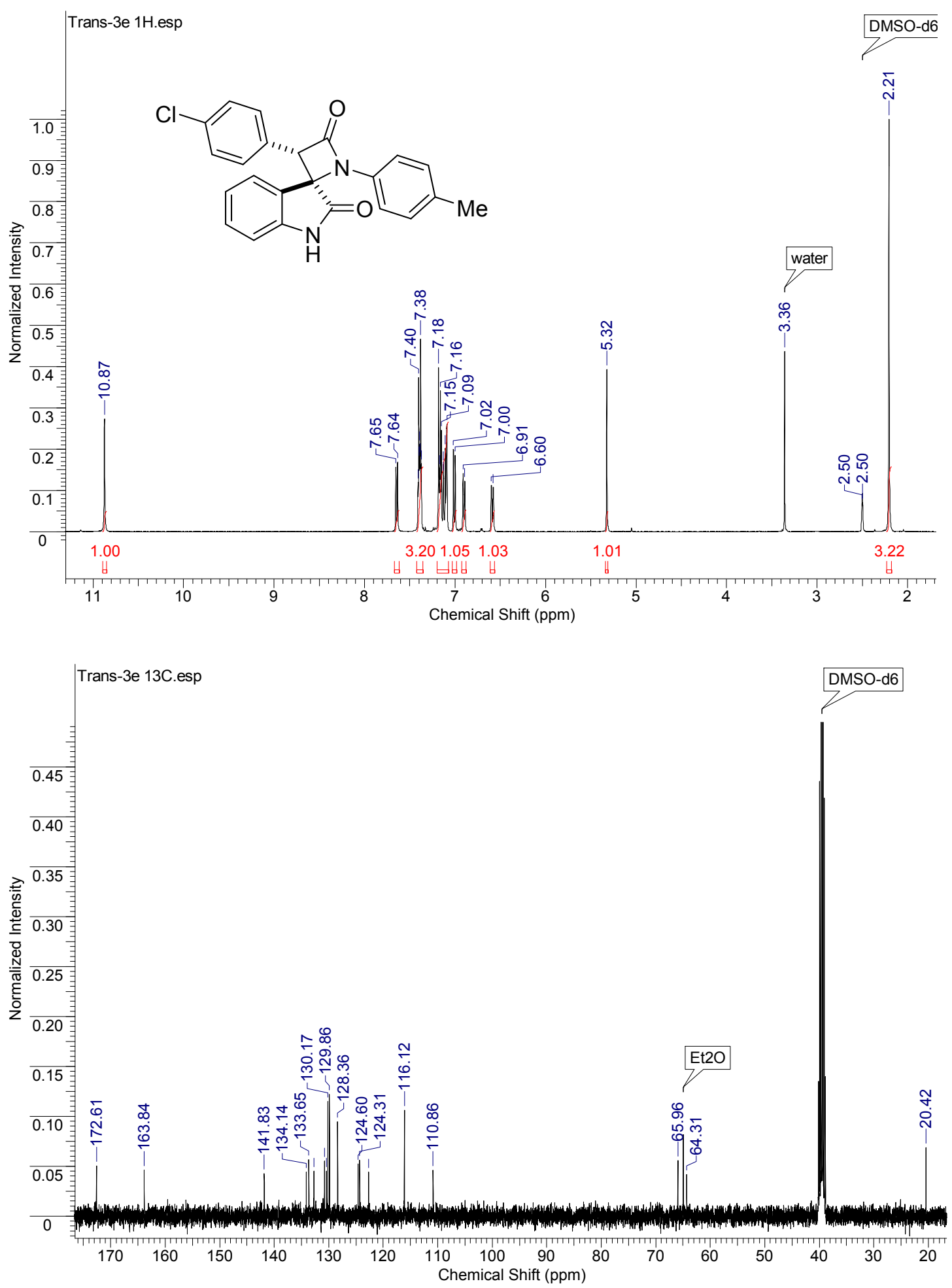

Figure S20. ${ }^{1} \mathrm{H}$ and ${ }^{13} \mathrm{C}$ NMR spectra of compound cis-3e 


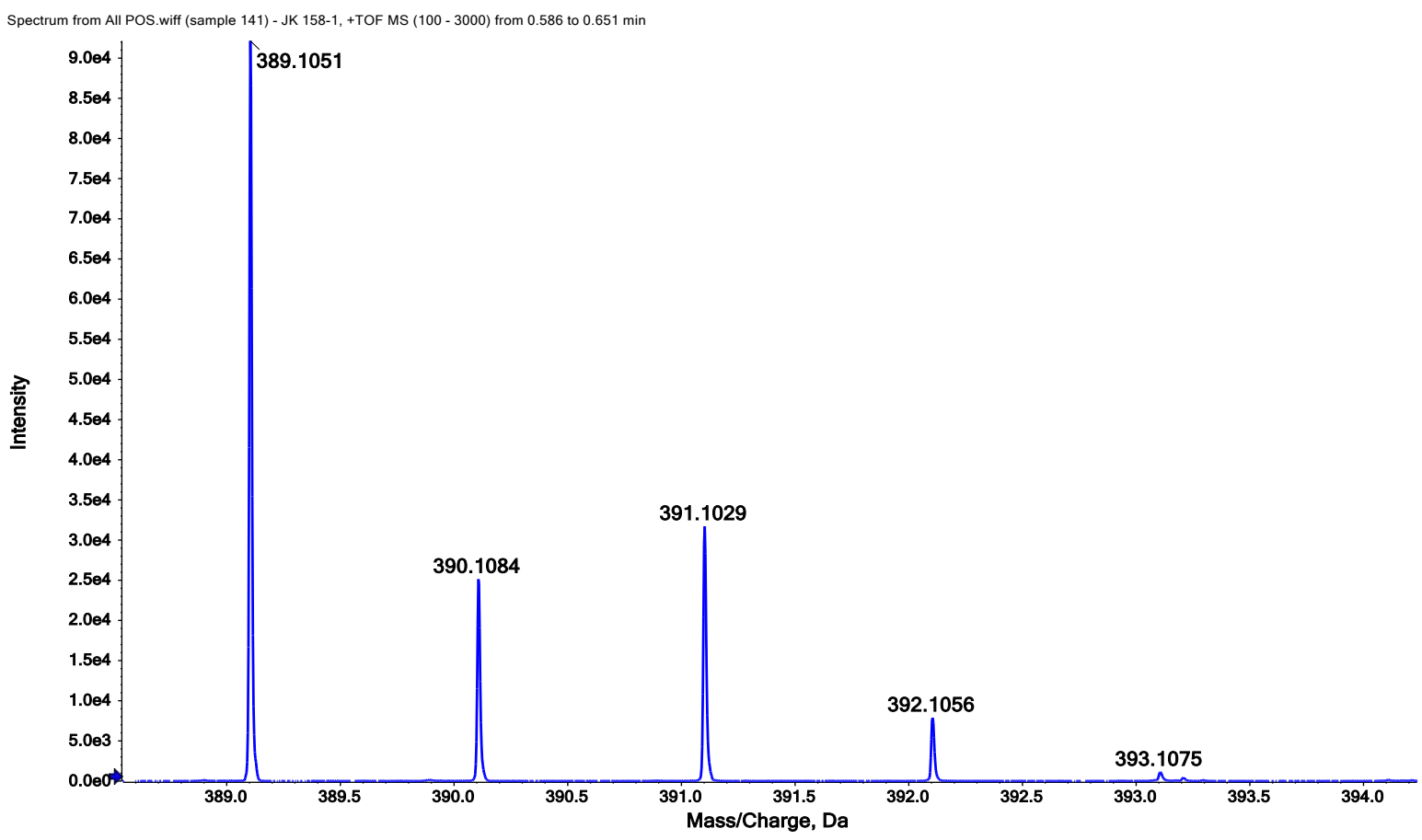

Figure S21. HRMS spectrum of compound cis-3e 

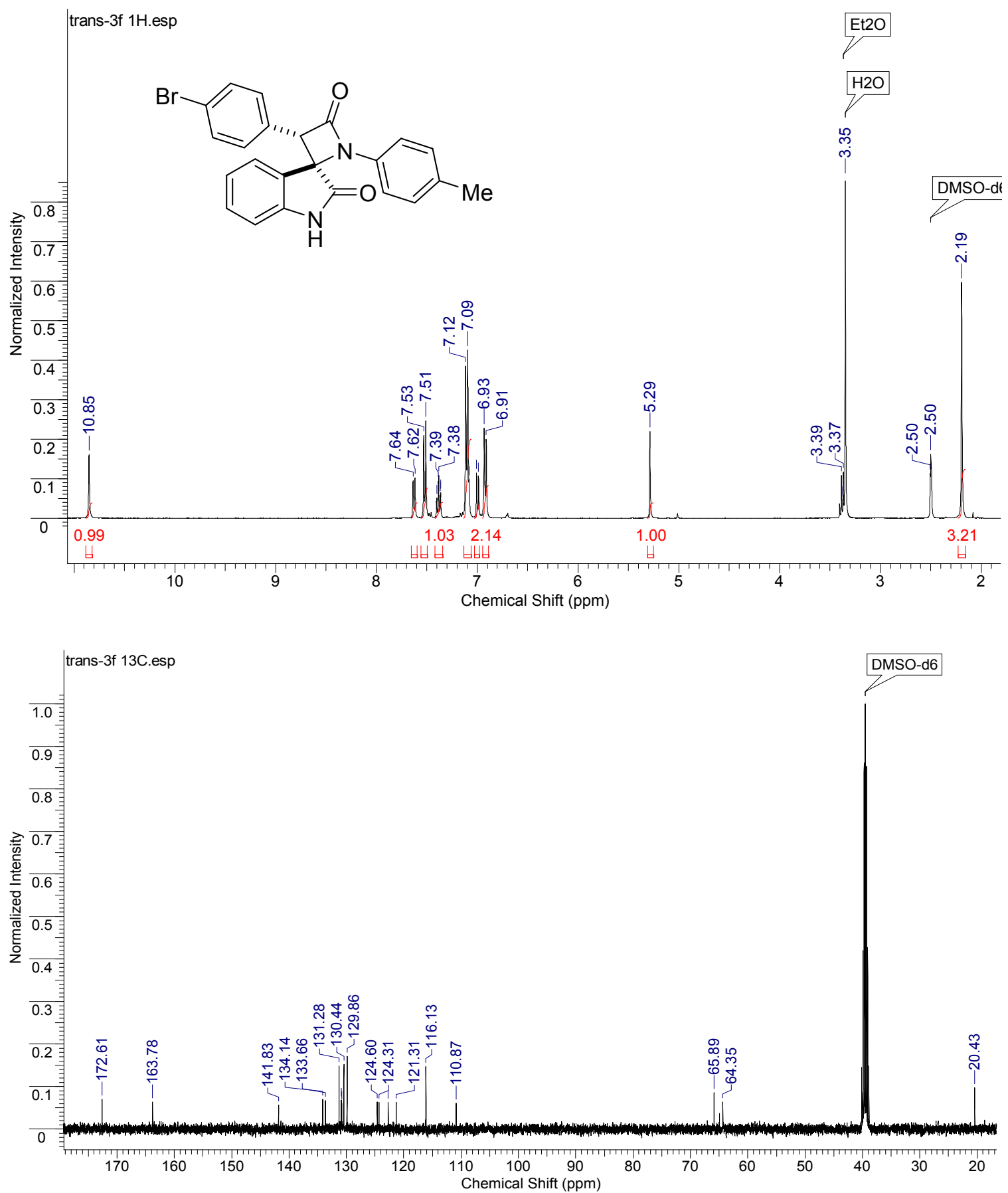

Figure S22. ${ }^{1} \mathrm{H}$ and ${ }^{13} \mathrm{C}$ NMR spectra of compound cis-3f 


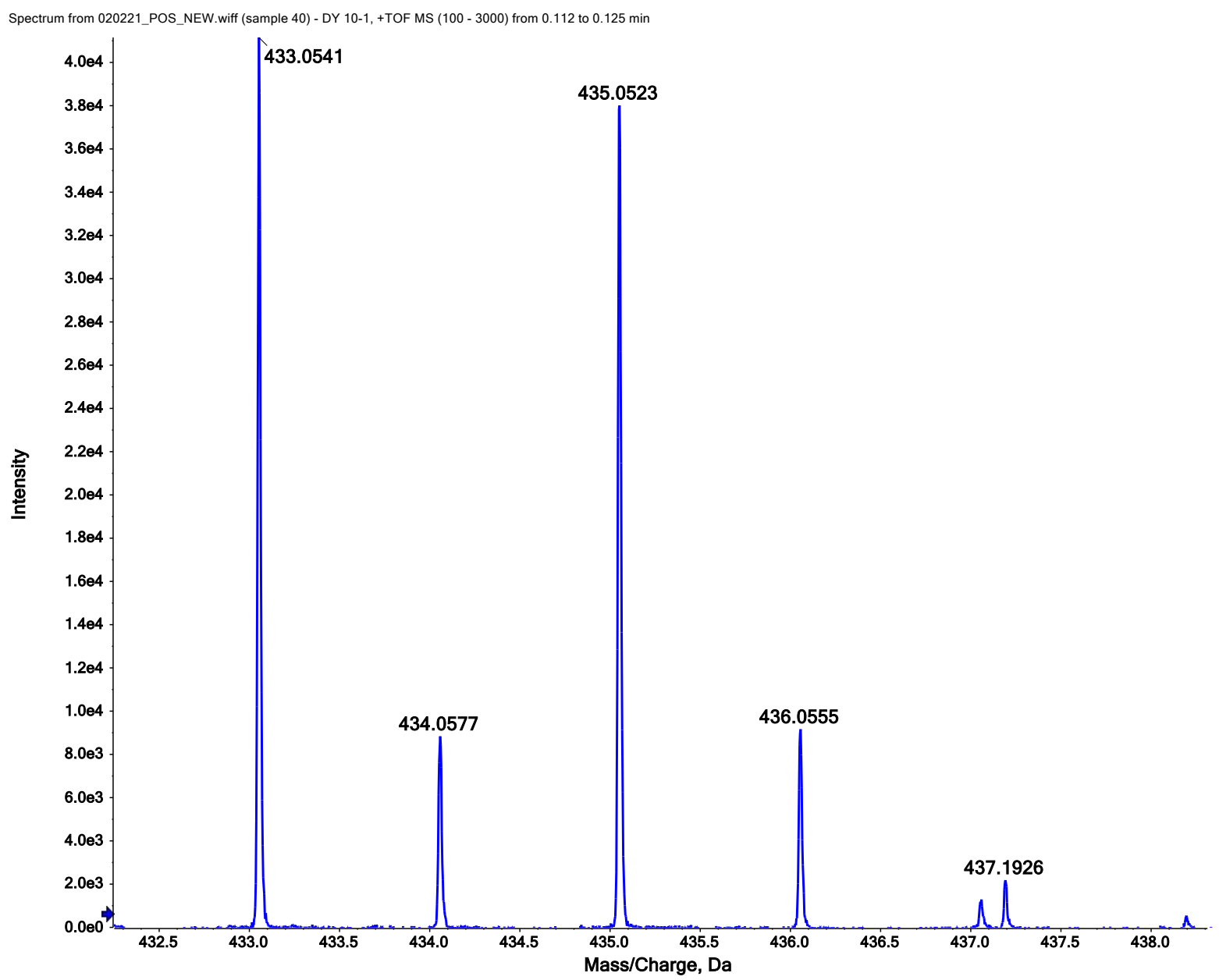

Figure S23. HRMS spectrum of compound cis-3f 

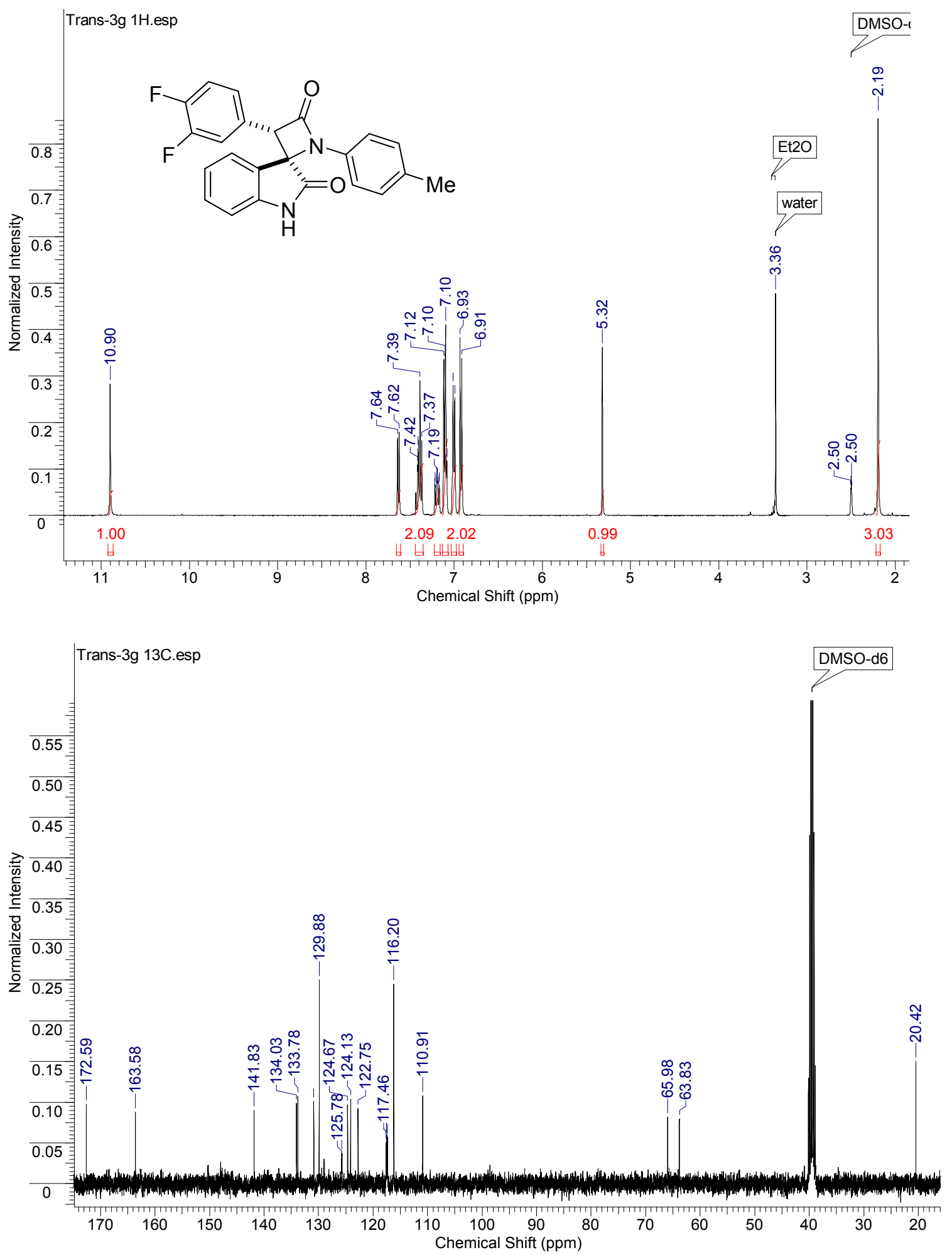

Figure S24. ${ }^{1} \mathrm{H}$ and ${ }^{13} \mathrm{C}$ NMR spectra of compound cis-3g 


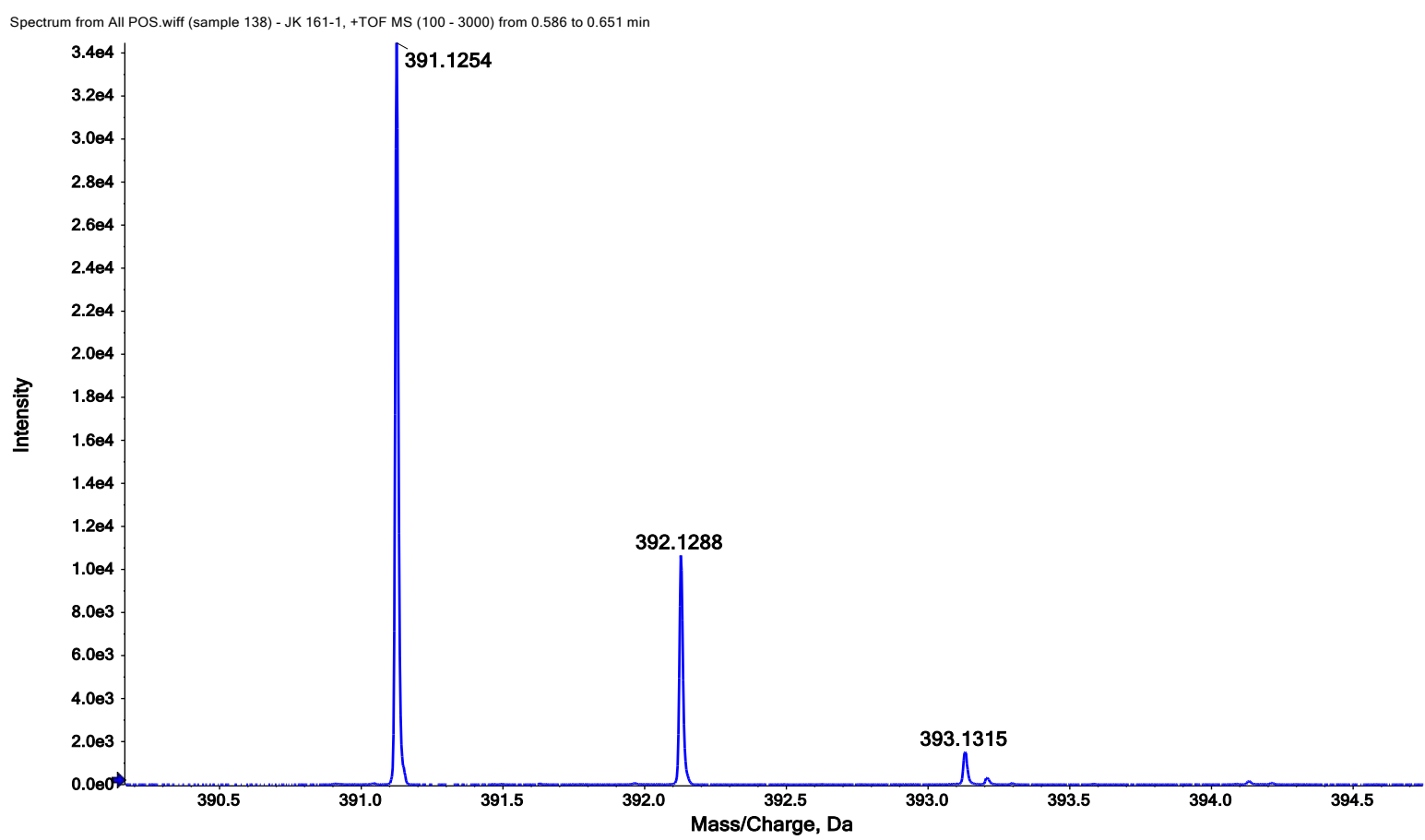

Figure S25. HRMS spectrum of compound cis-3g 

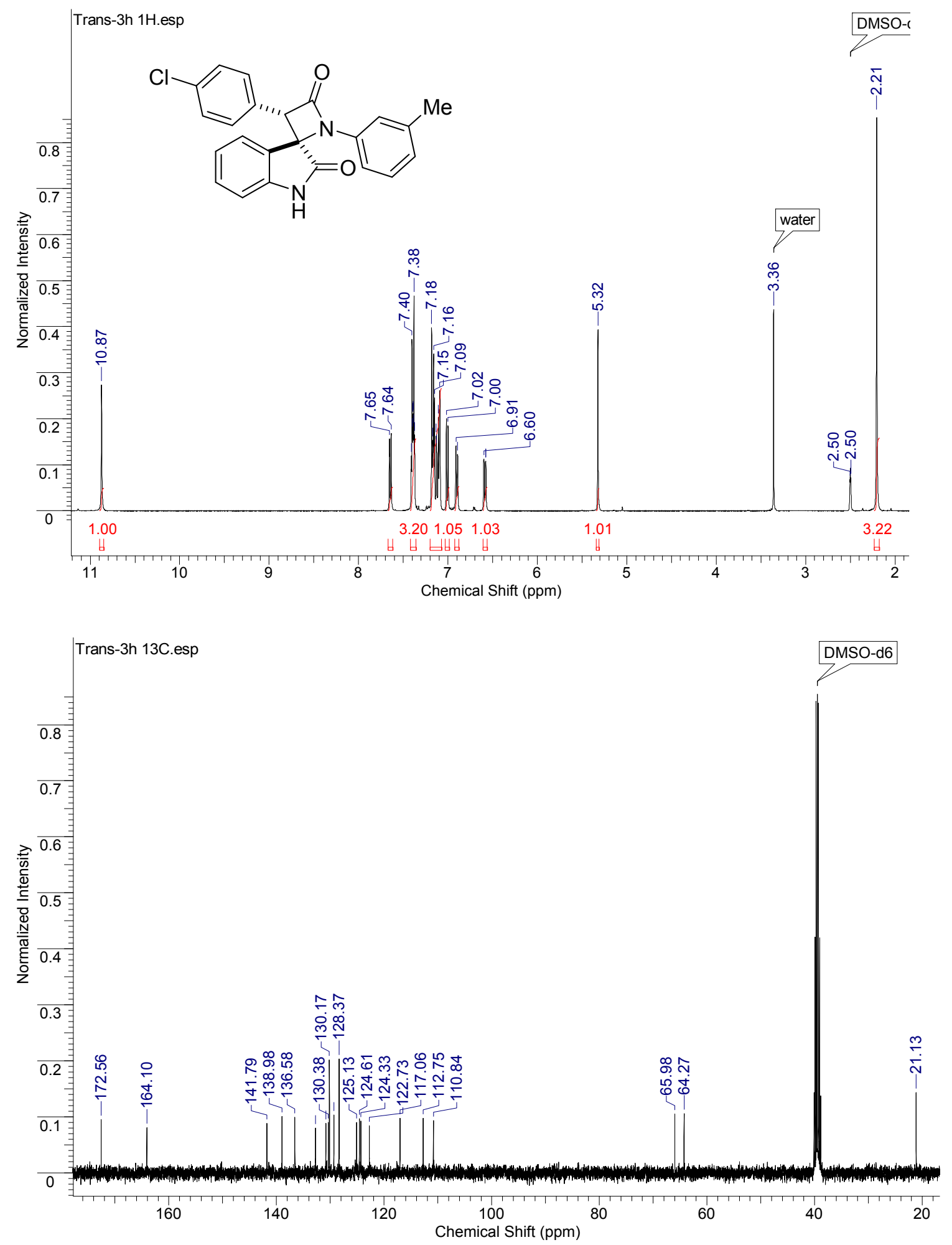

Figure S26. ${ }^{1} \mathrm{H}$ and ${ }^{13} \mathrm{C}$ NMR spectra of compound cis-3h 


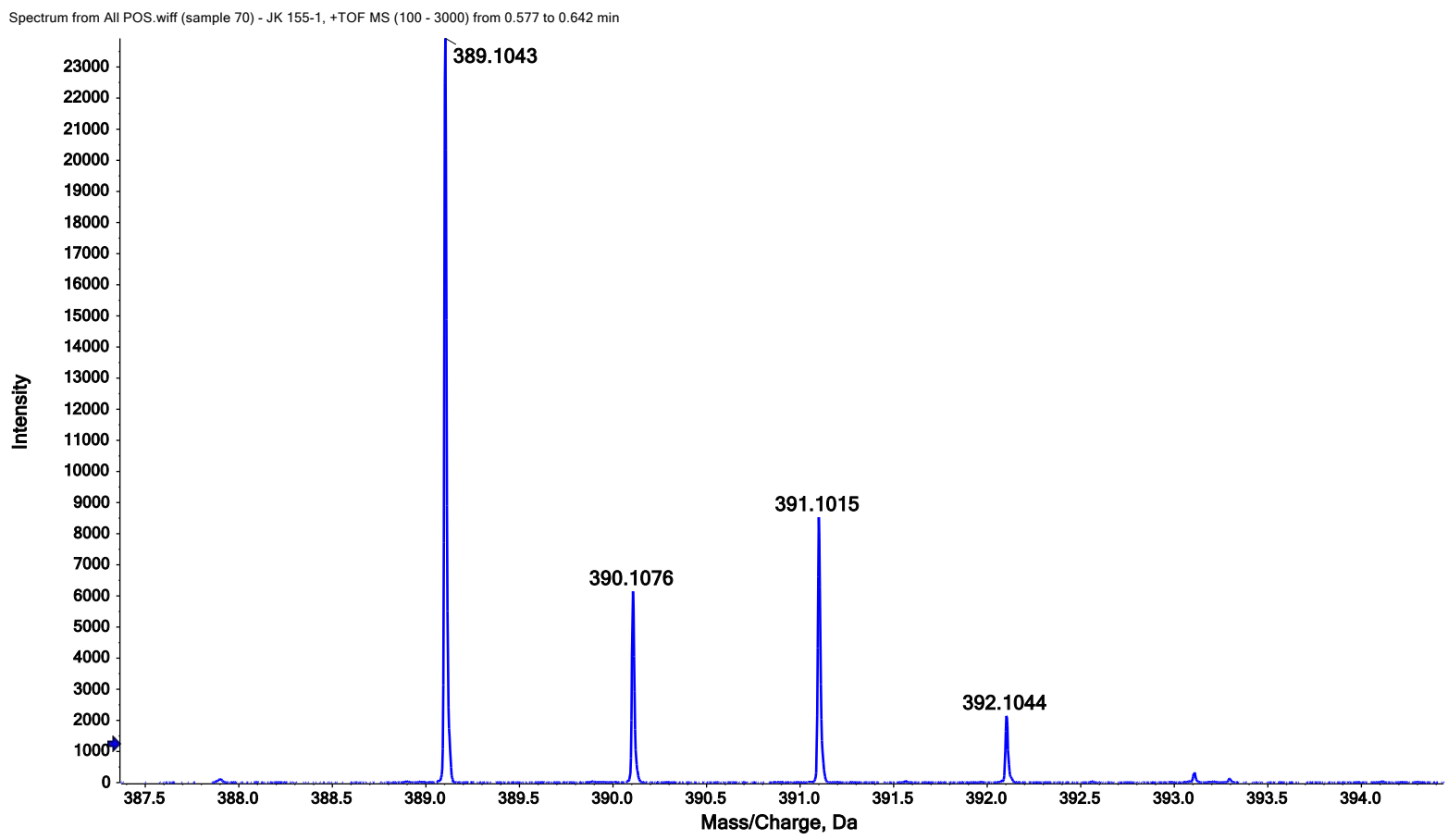

Figure S27. HRMS spectrum of compound cis-3h 

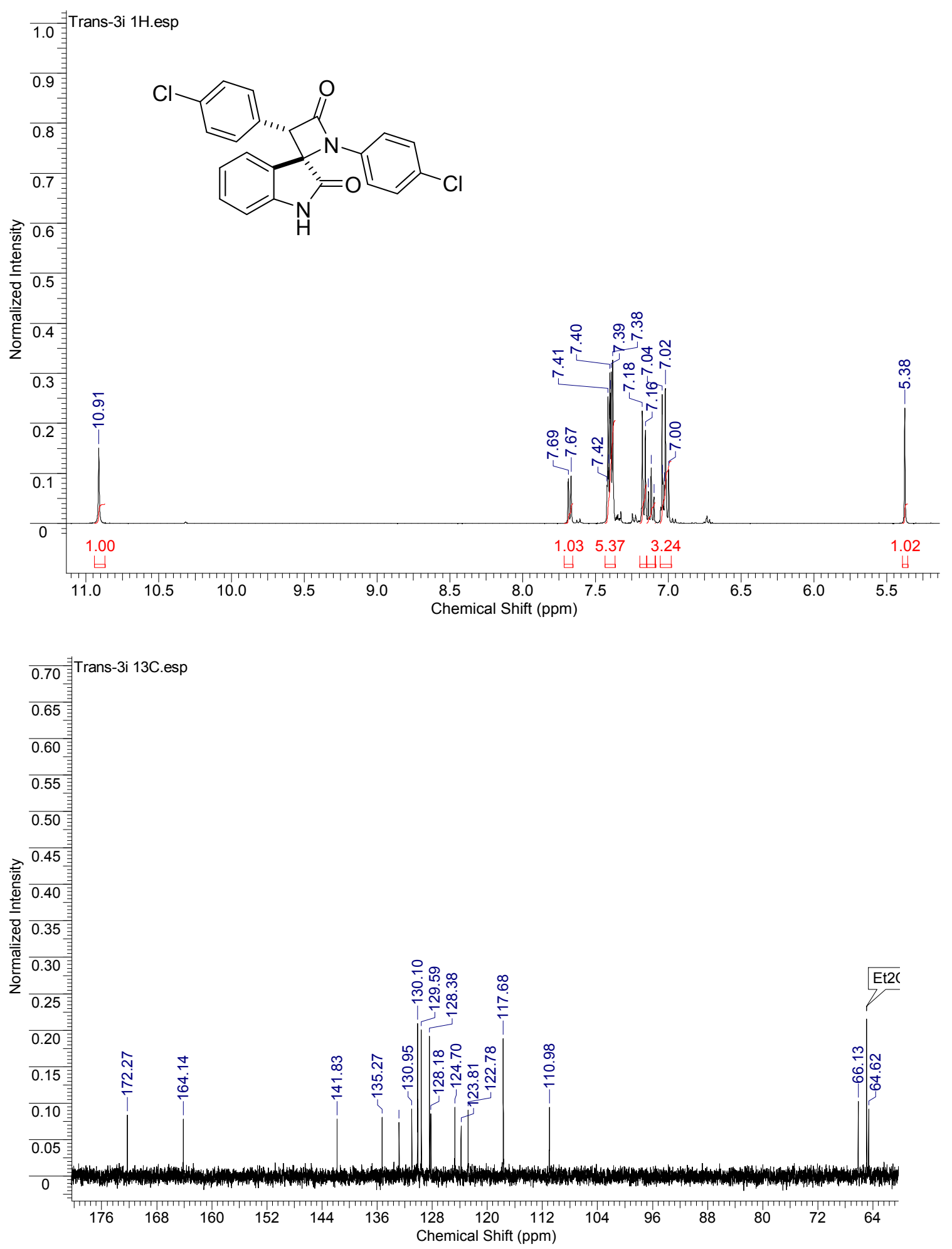

Figure S28. ${ }^{1} \mathrm{H}$ and ${ }^{13} \mathrm{C}$ NMR spectra of compound cis-3i 


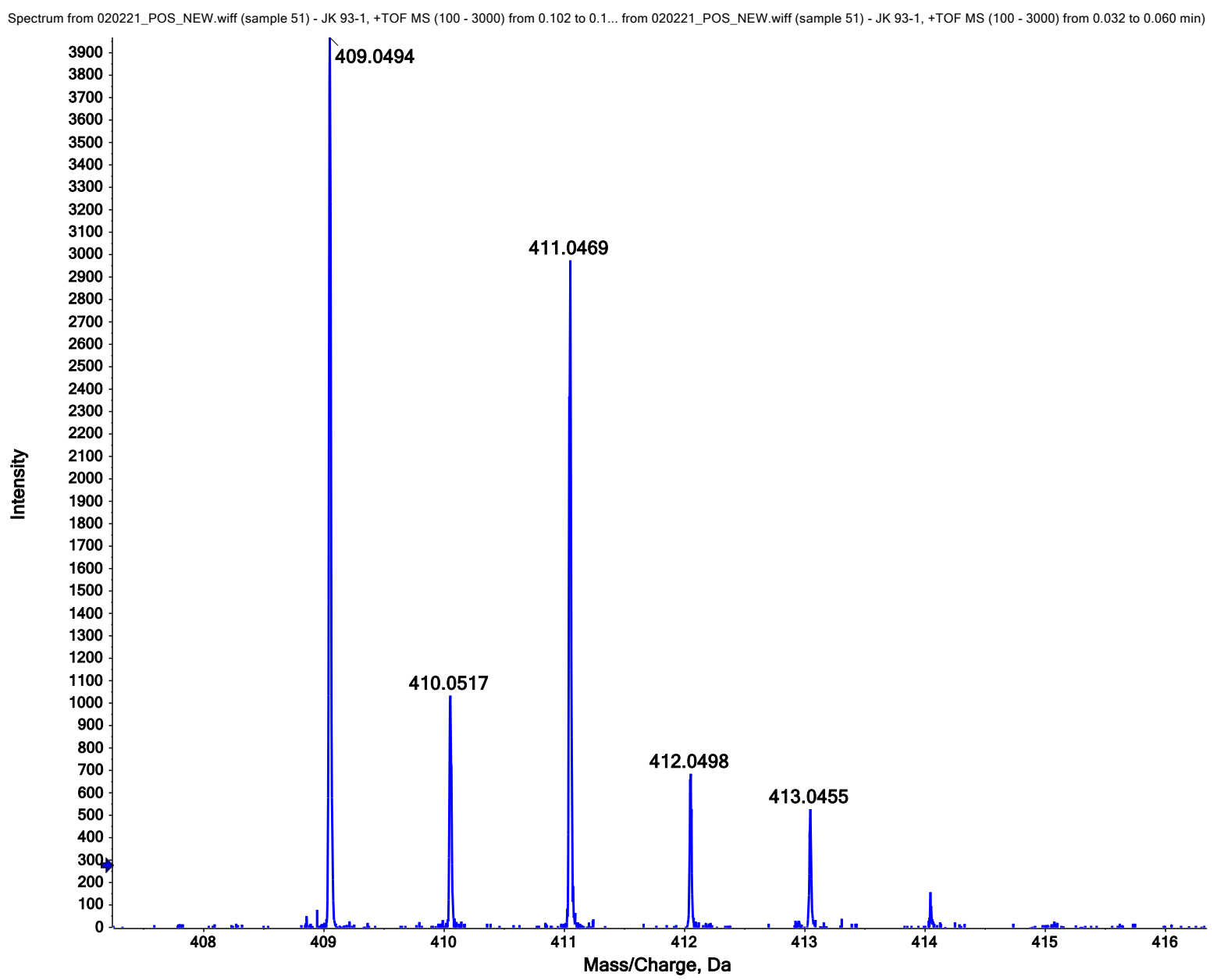

Figure S29. HRMS spectrum of compound cis-3i 
(cis-3i)
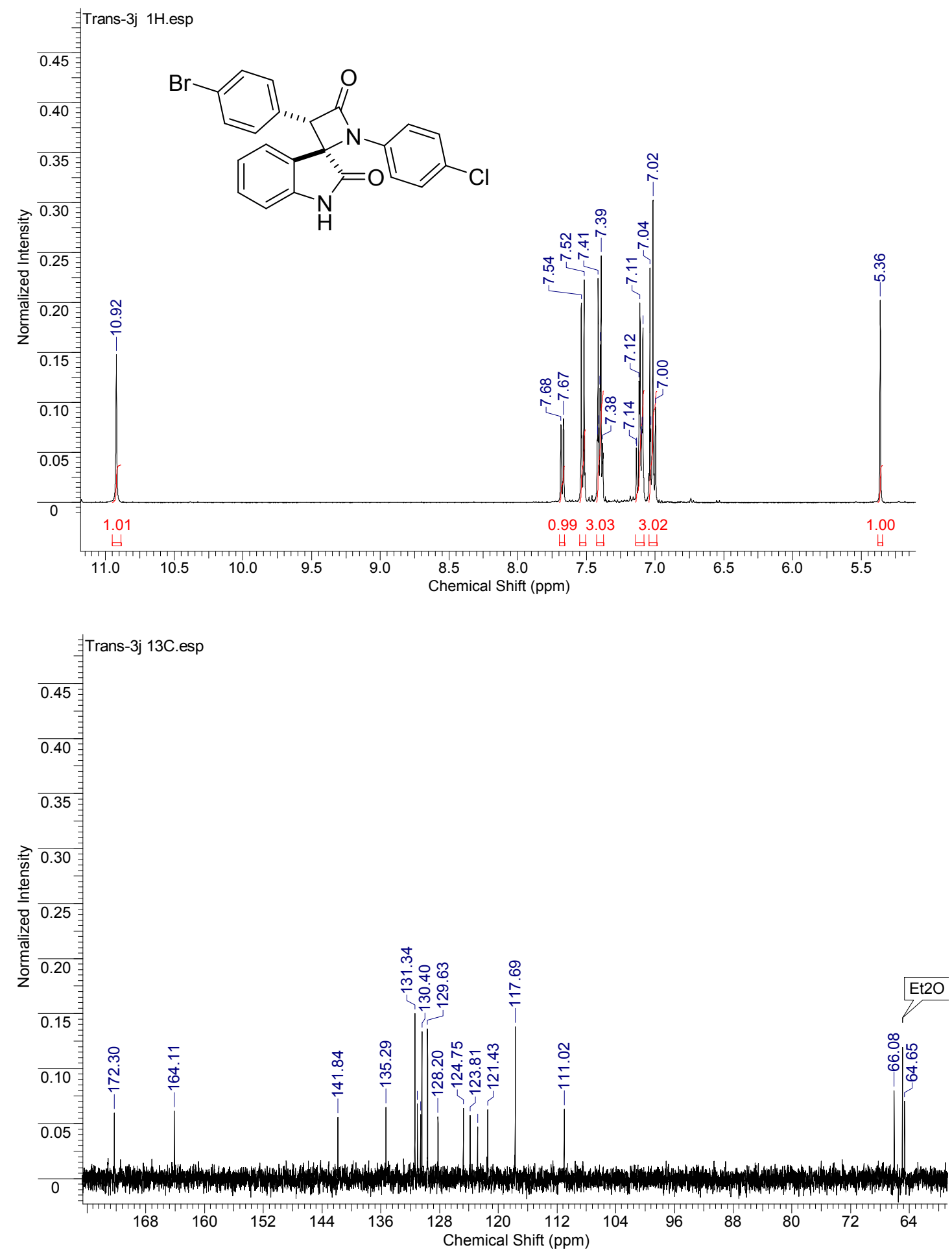

Figure S30. ${ }^{1} \mathrm{H}$ and ${ }^{13} \mathrm{C}$ NMR spectra of compound cis-3j 


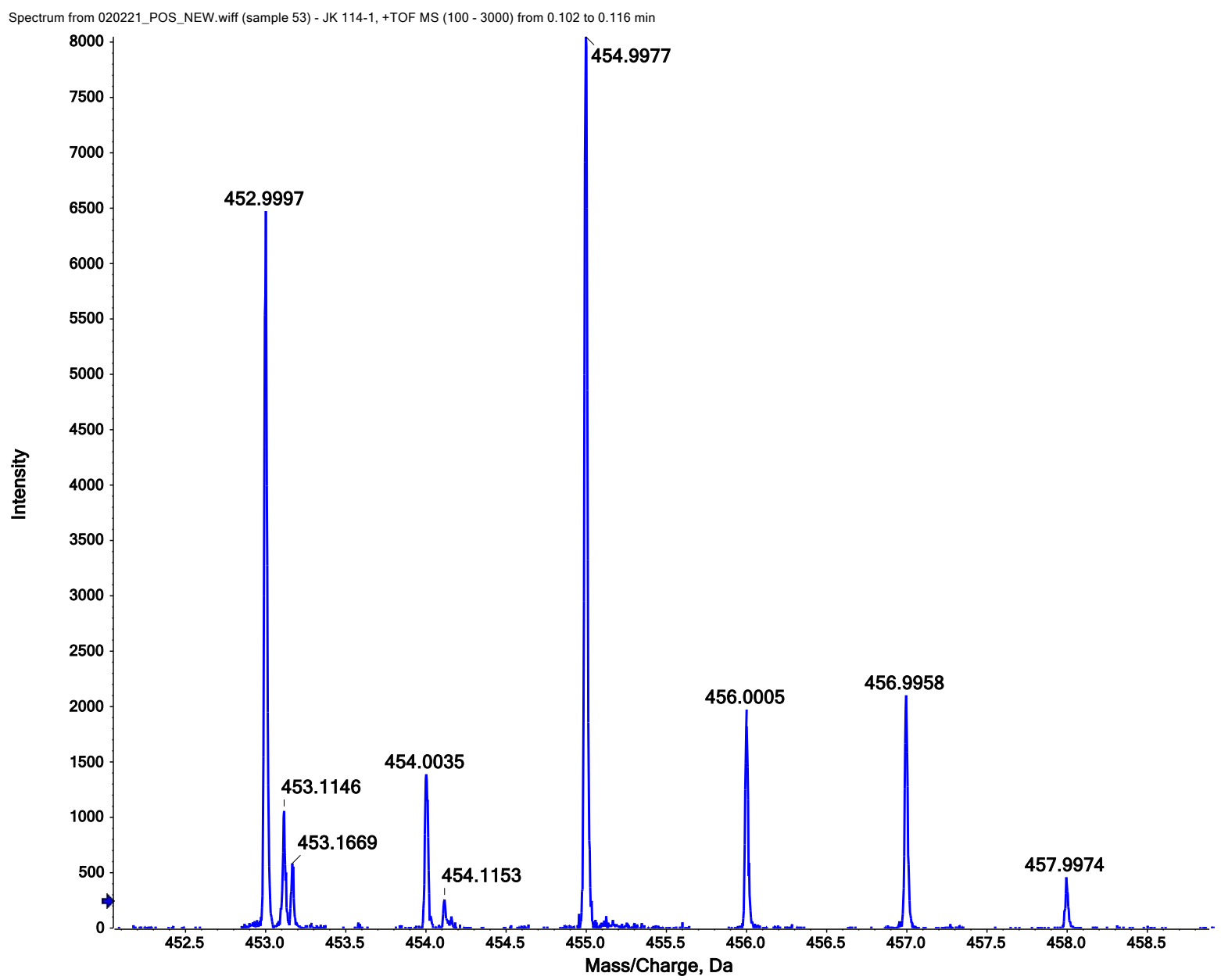

Figure S31. HRMS spectrum of compound cis-3j 

dione (cis-3k)
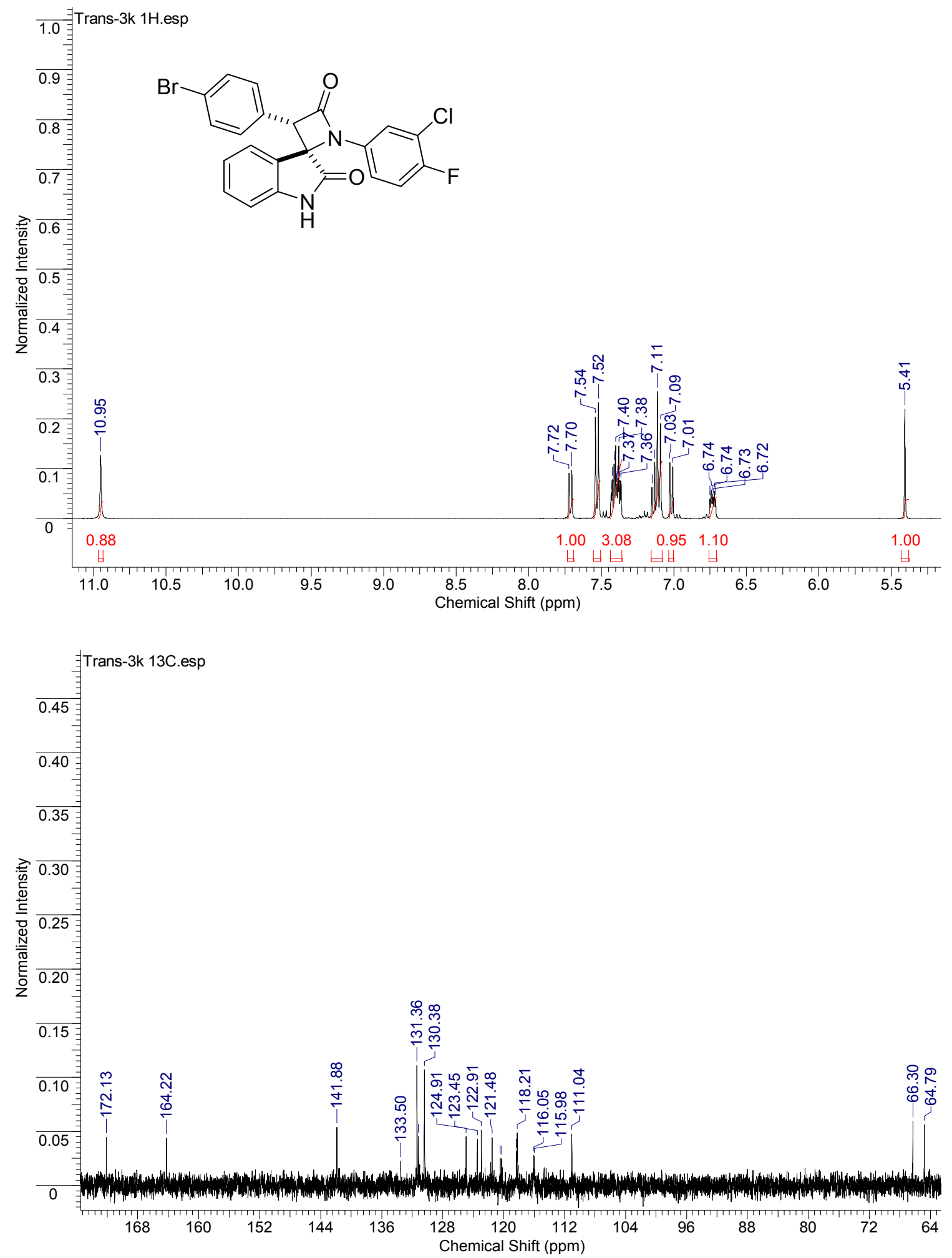

Figure S32. ${ }^{1} \mathrm{H}$ and ${ }^{13} \mathrm{C}$ NMR spectra of compound cis-3k 
Spectrum from 050321_POS.wiff (sample 47) - JK 148 1, +TOF MS (100 - 3000) from 0.079...050321_POS. wiff (sample 47) - JK 148 1, +TOF MS (100 - 3000$)$ from 0.033 to 0.065 min)

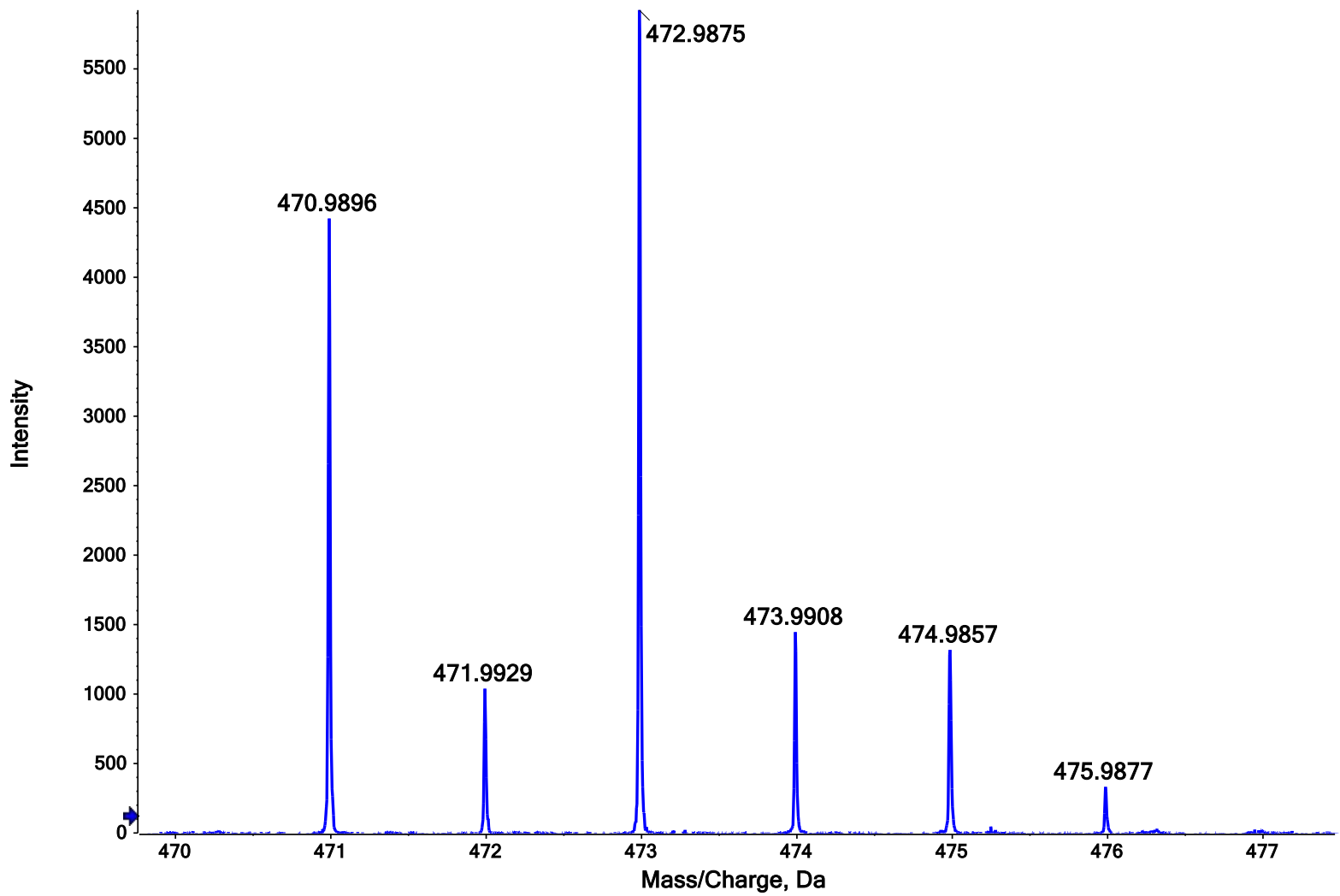

Figure S33. HRMS spectrum of compound cis-3k 

dione (trans-3k)
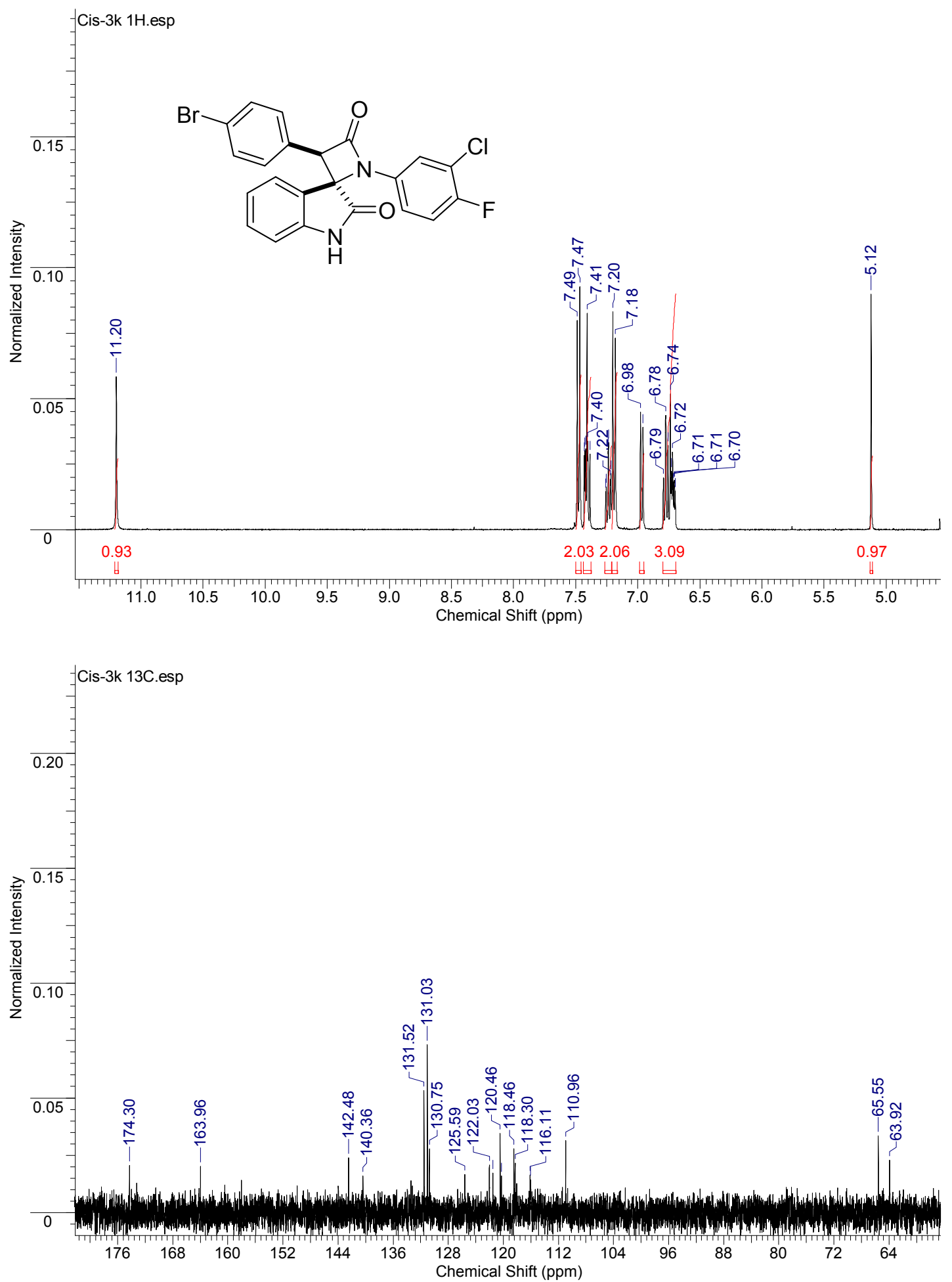

Figure $\mathrm{S} 34 .{ }^{1} \mathrm{H}$ and ${ }^{13} \mathrm{C}$ NMR spectra of compound trans-3k 


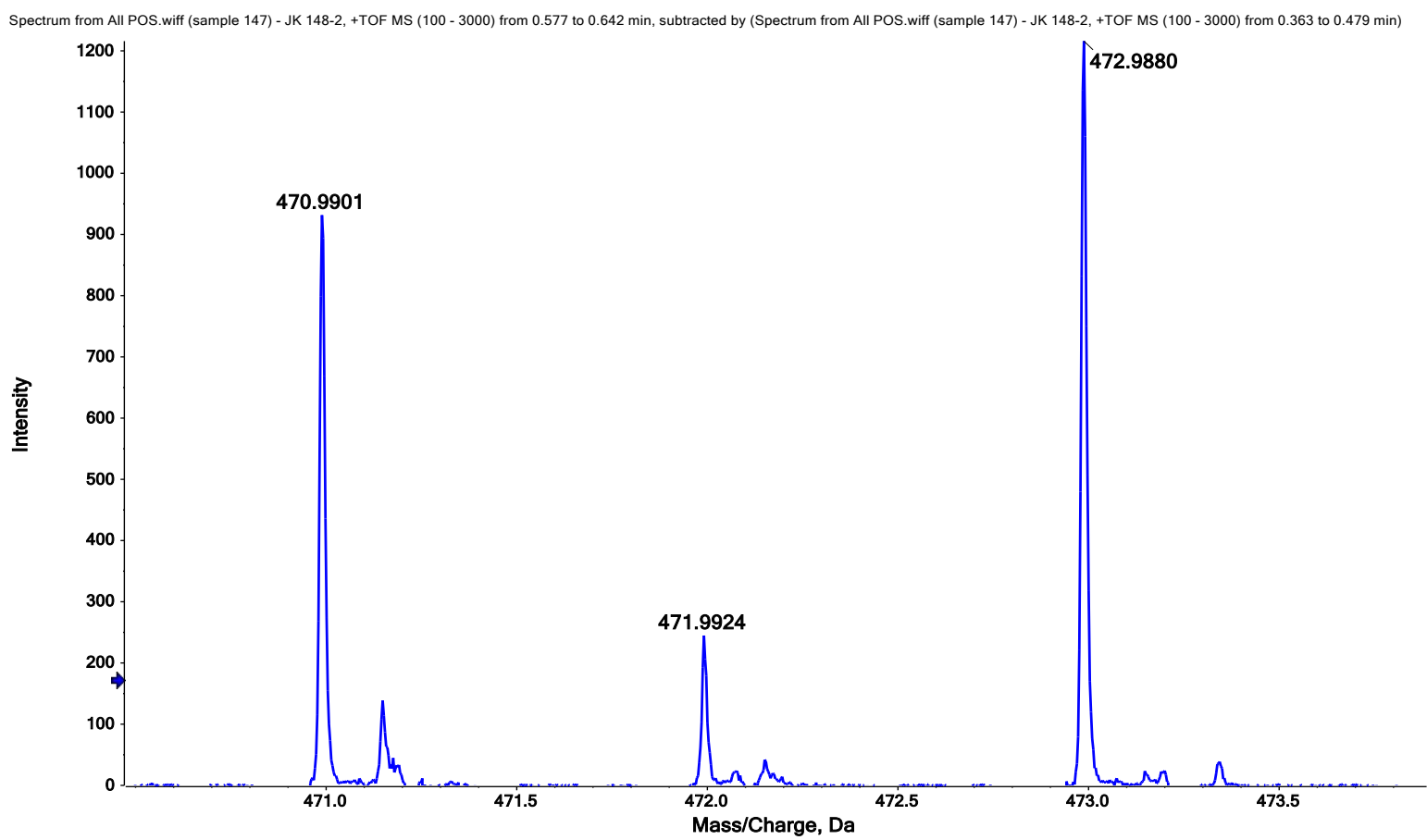

Figure S35. HRMS spectrum of compound trans-3k 
(cis-3l)
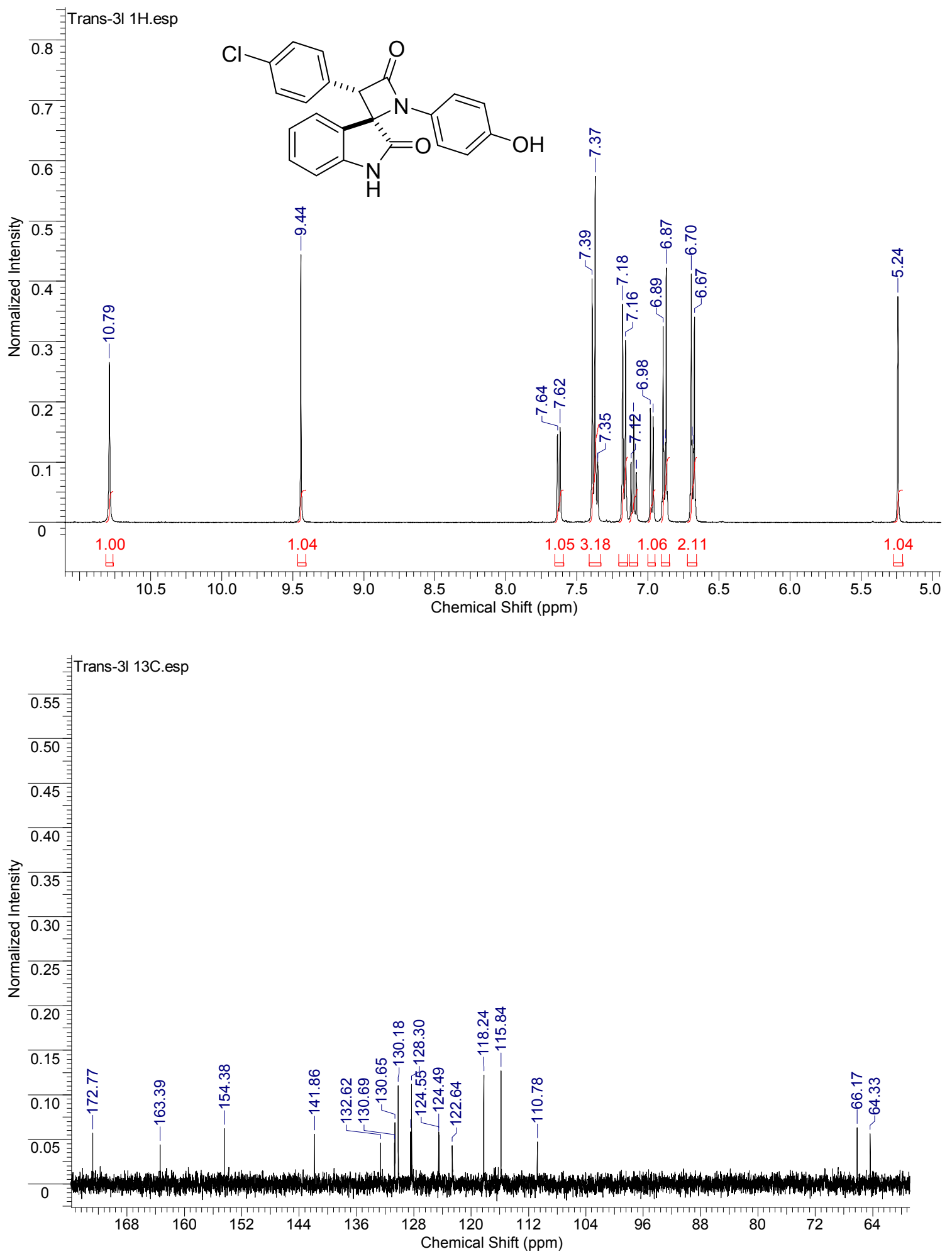

Figure S36. ${ }^{1} \mathrm{H}$ and ${ }^{13} \mathrm{C}$ NMR spectra of compound cis-31 


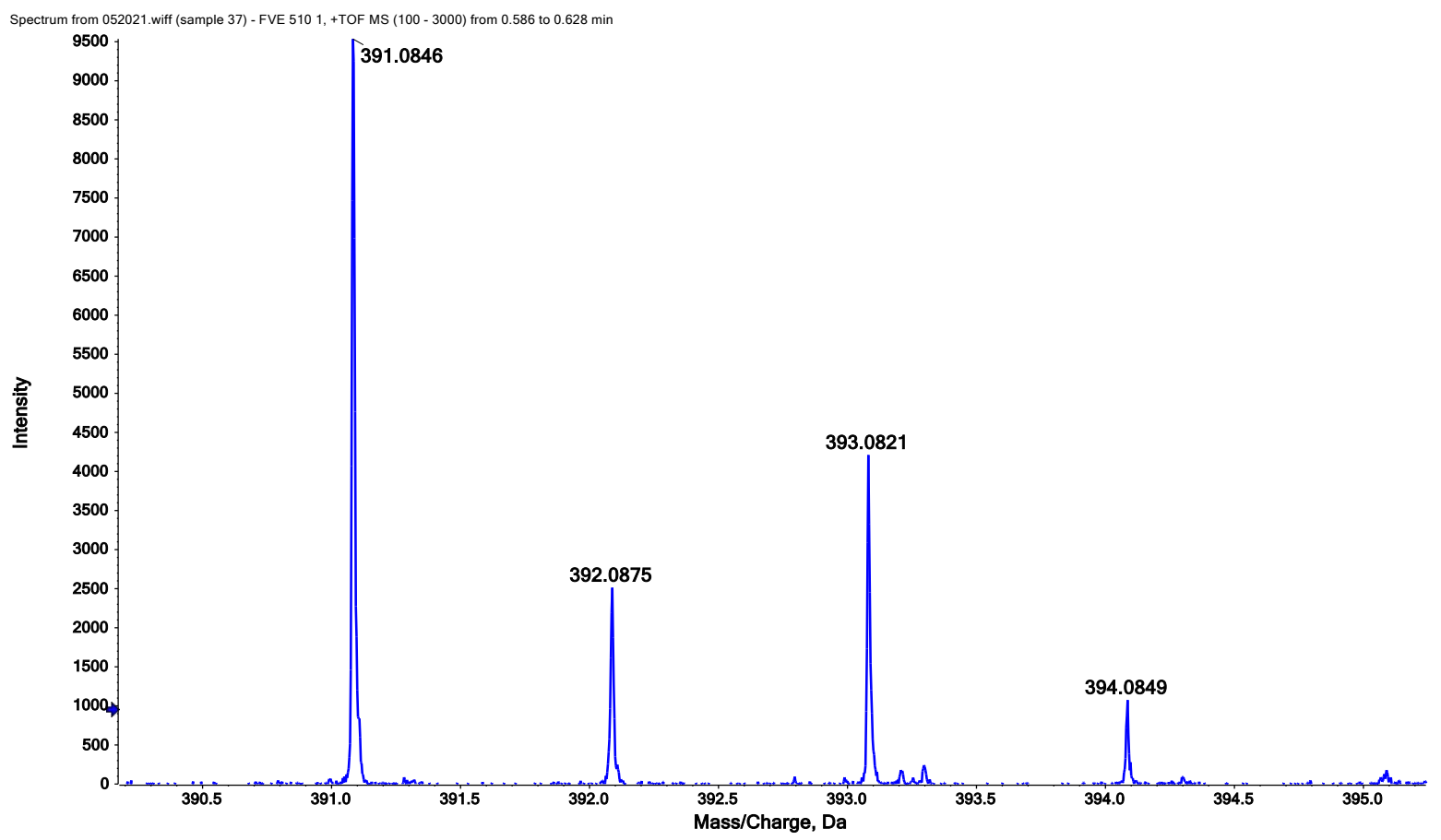

Figure S37. HRMS spectrum of compound cis-3I 
(trans-3l)
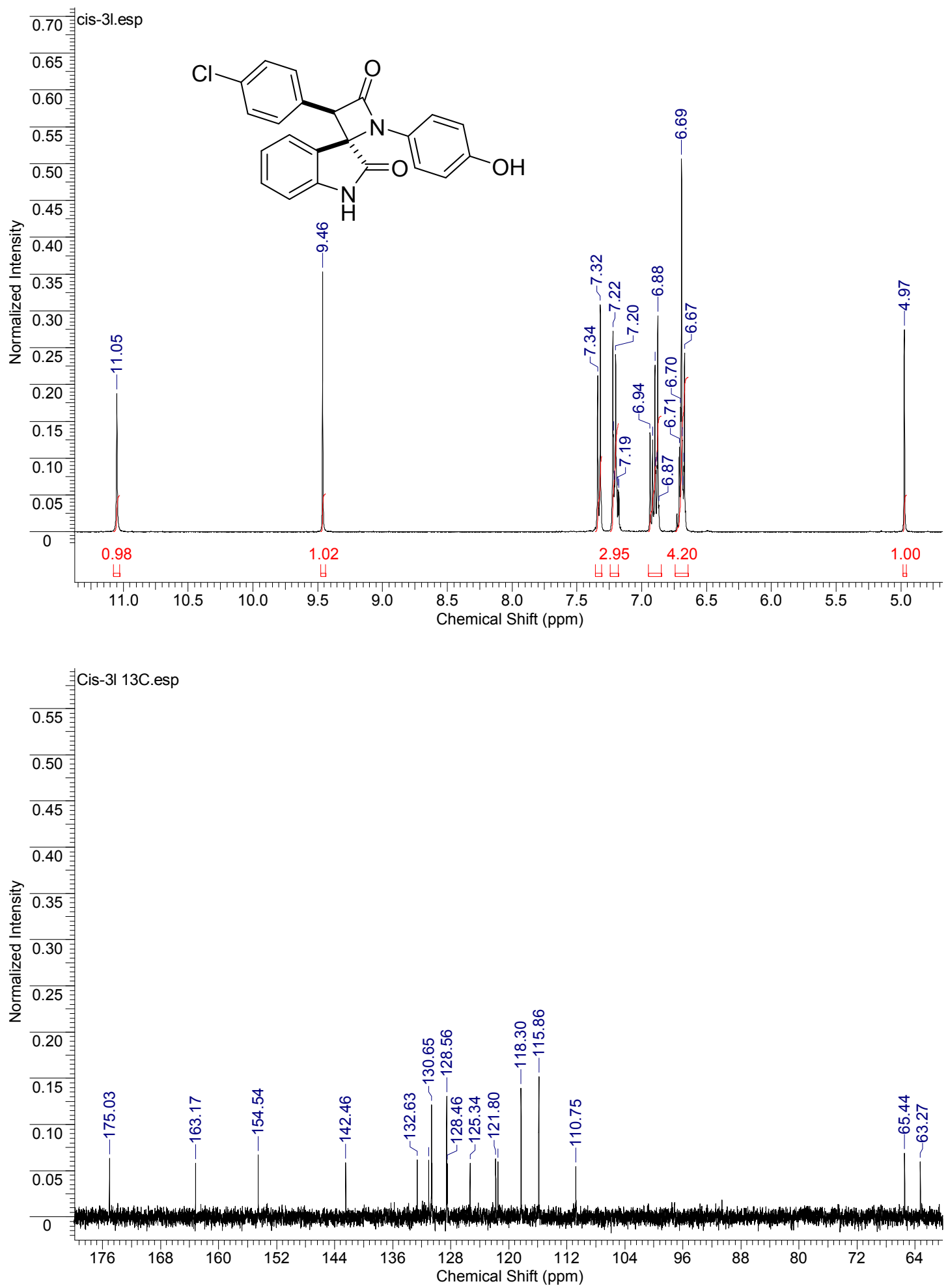

Figure S38. ${ }^{1} \mathrm{H}$ and ${ }^{13} \mathrm{C}$ NMR spectra of compound trans-3I 


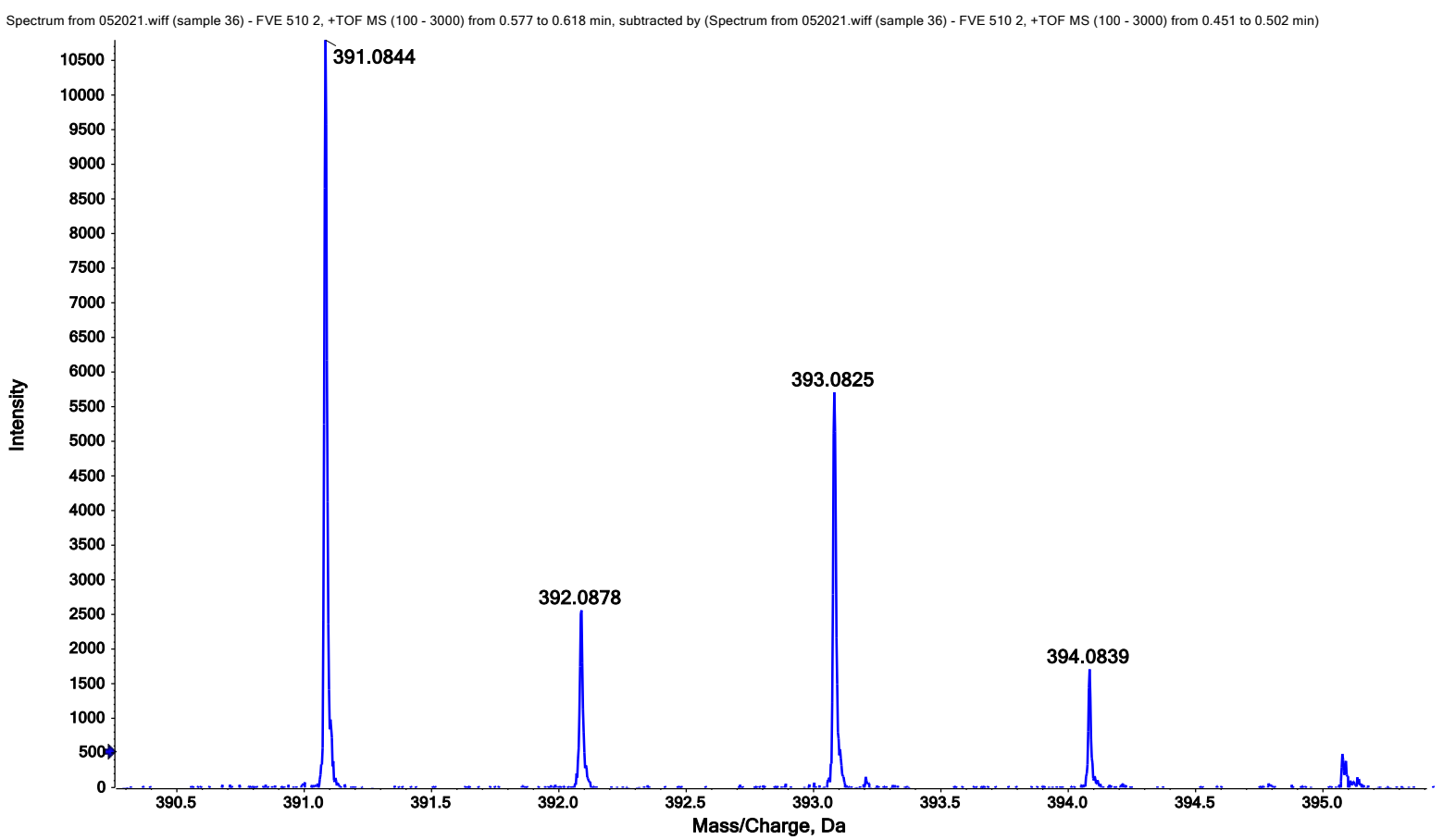

Figure S39. HRMS spectrum of compound trans-31 

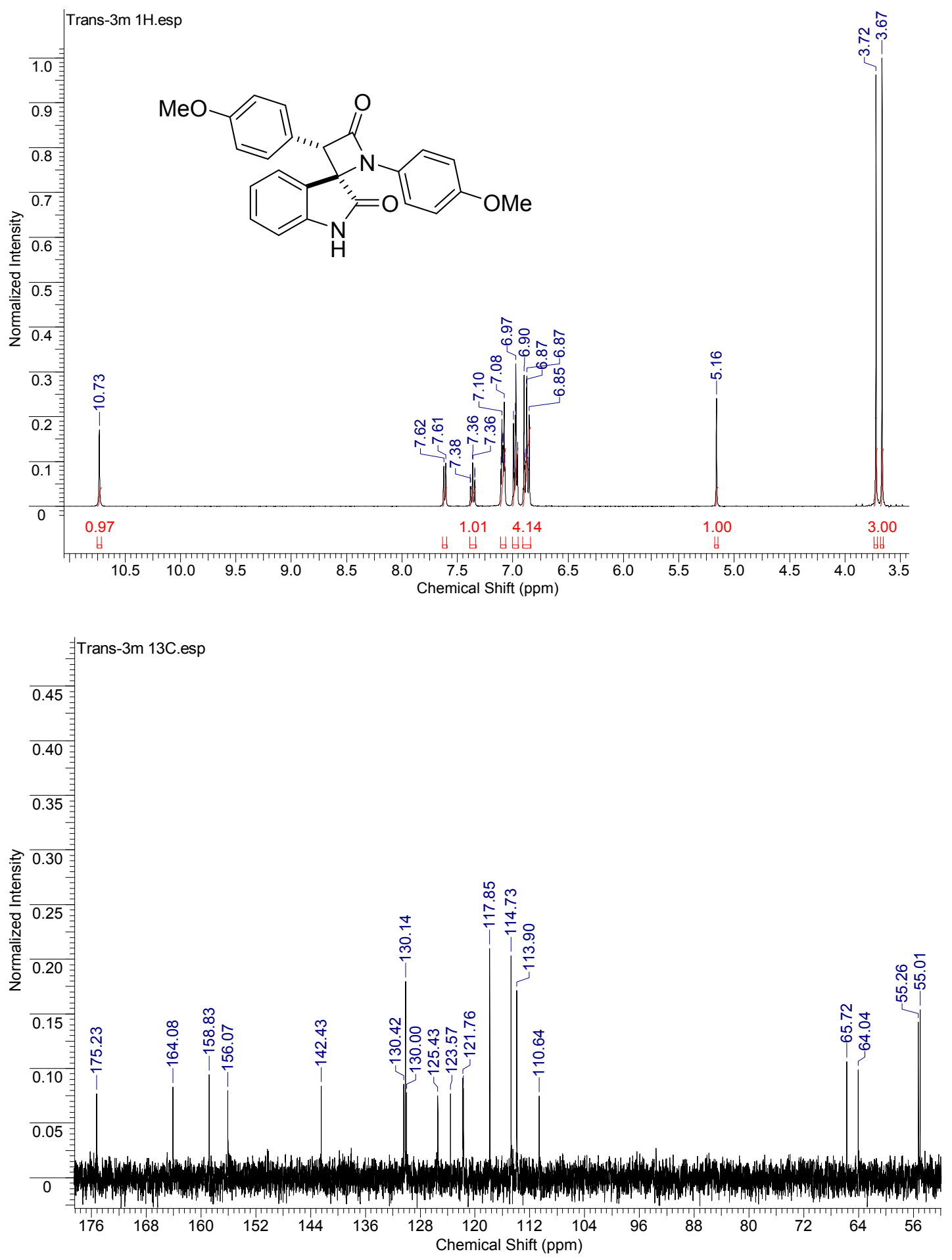

Figure S40. ${ }^{1} \mathrm{H}$ and ${ }^{13} \mathrm{C}$ NMR spectra of compound cis-3m 


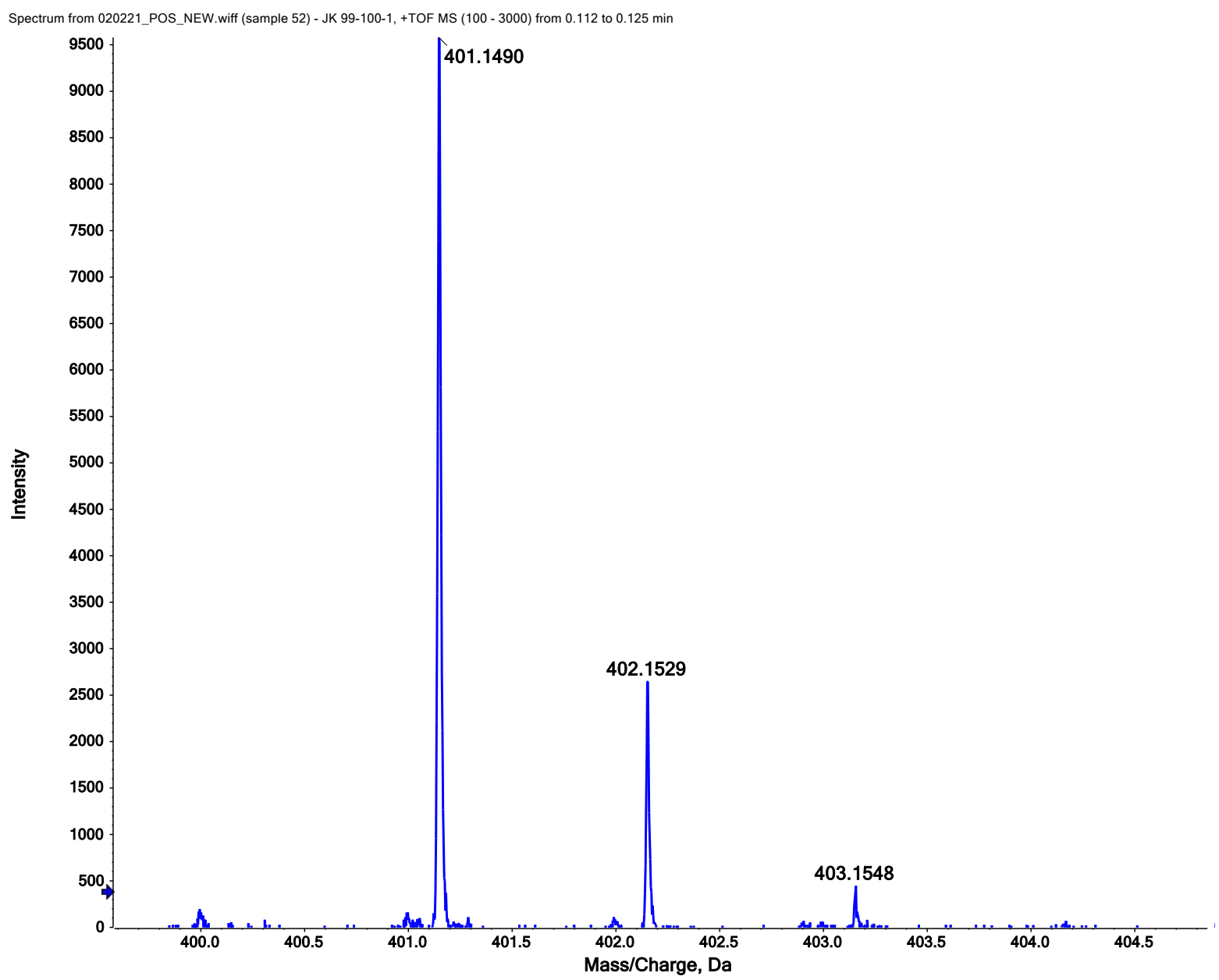

Figure S41. HRMS spectrum of compound cis-3m 

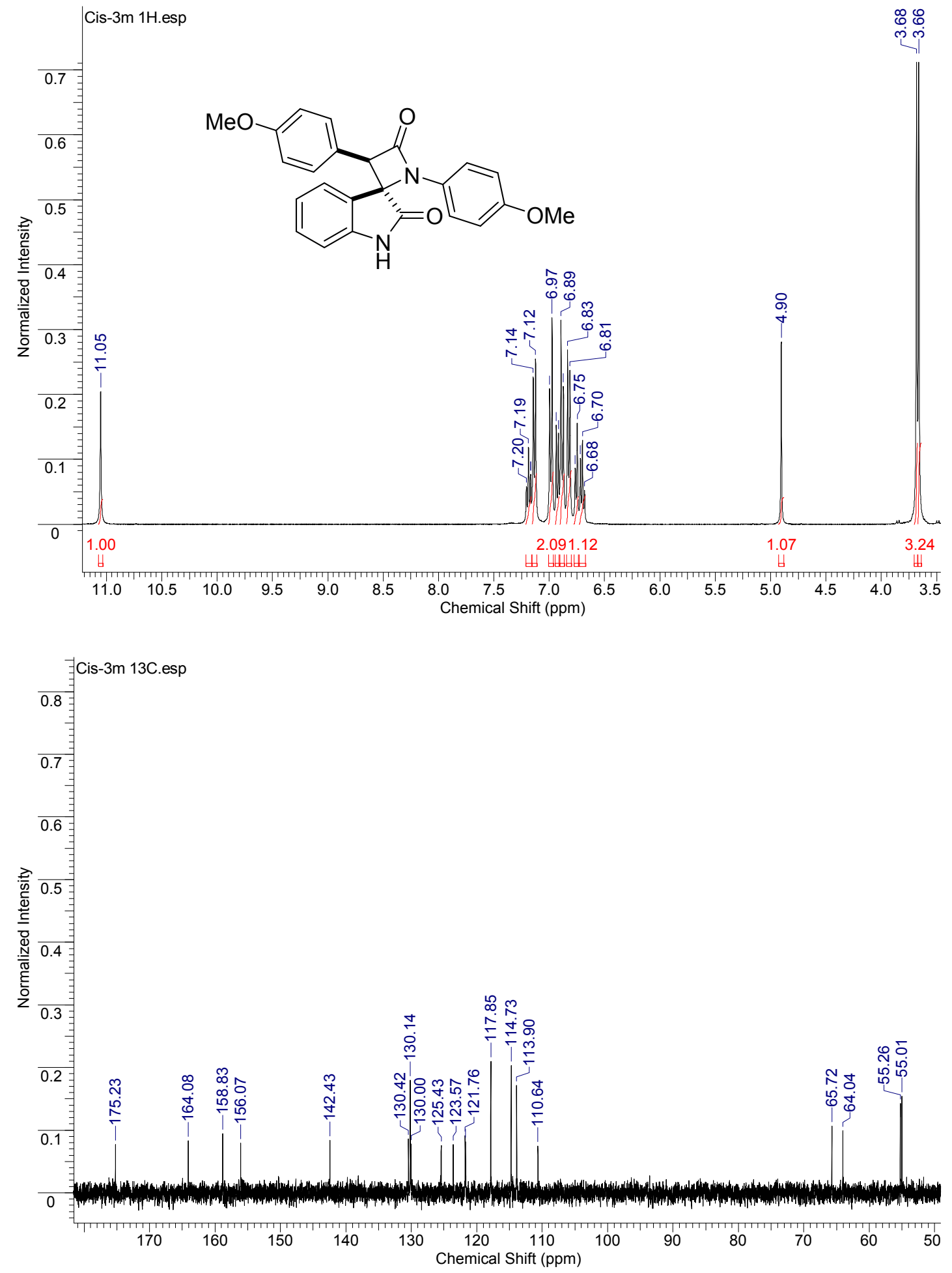

Figure $\mathrm{S} 42 .{ }^{1} \mathrm{H}$ and ${ }^{13} \mathrm{C}$ NMR spectra of compound trans-3m 


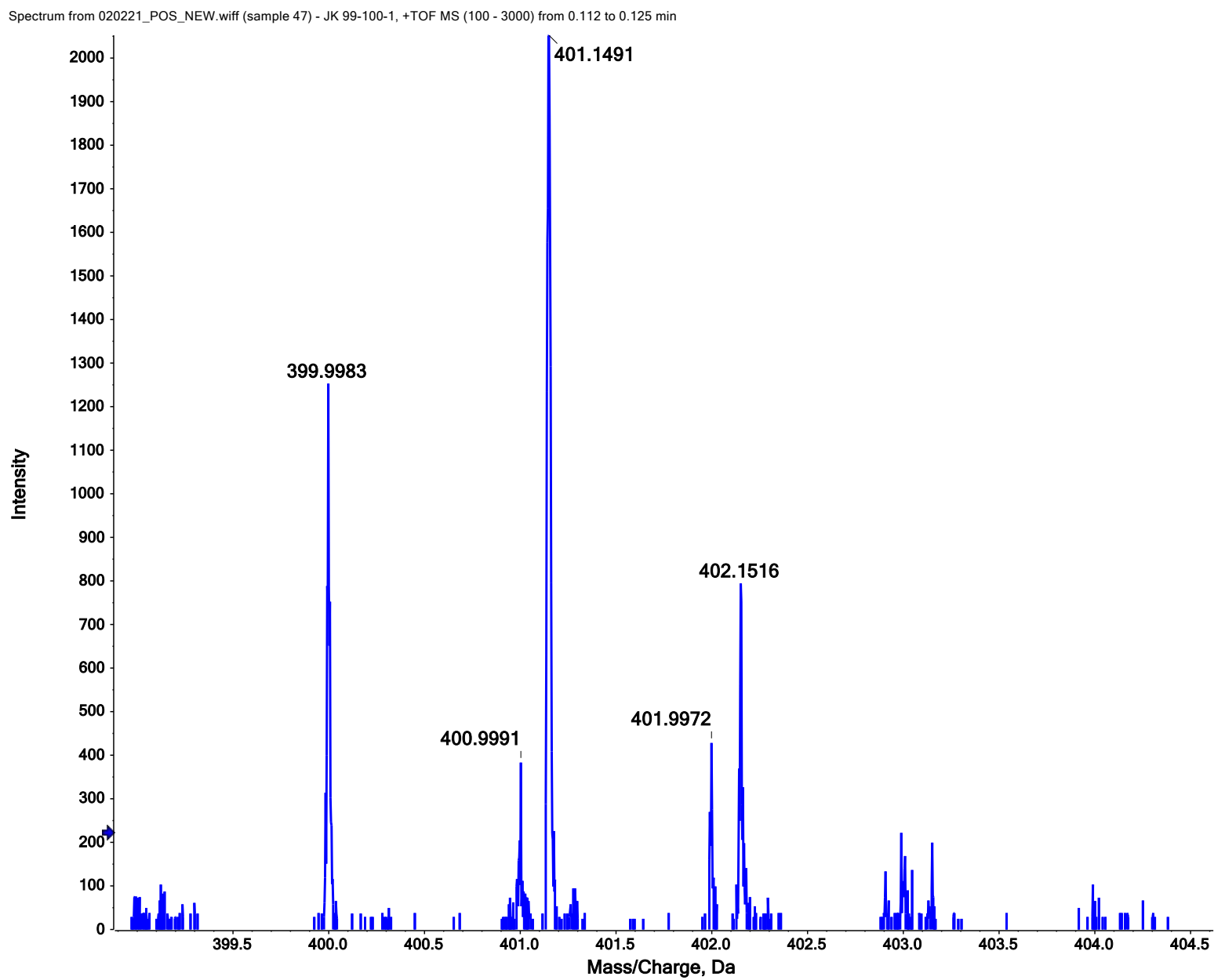

Figure S43. HRMS spectrum of compound trans-3m 
(trans-3n)
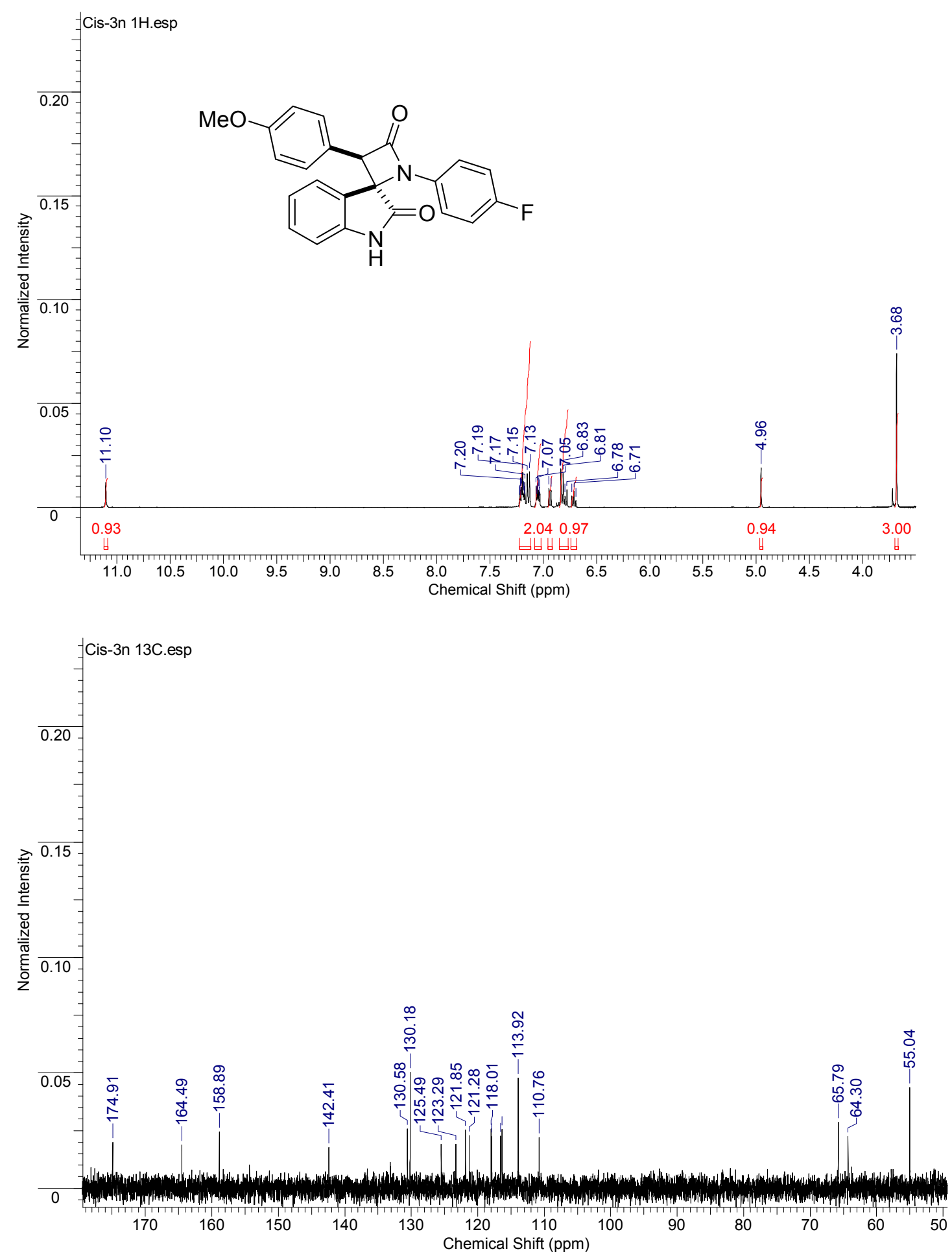

Figure S44. ${ }^{1} \mathrm{H}$ and ${ }^{13} \mathrm{C}$ NMR spectra of compound trans-3n 


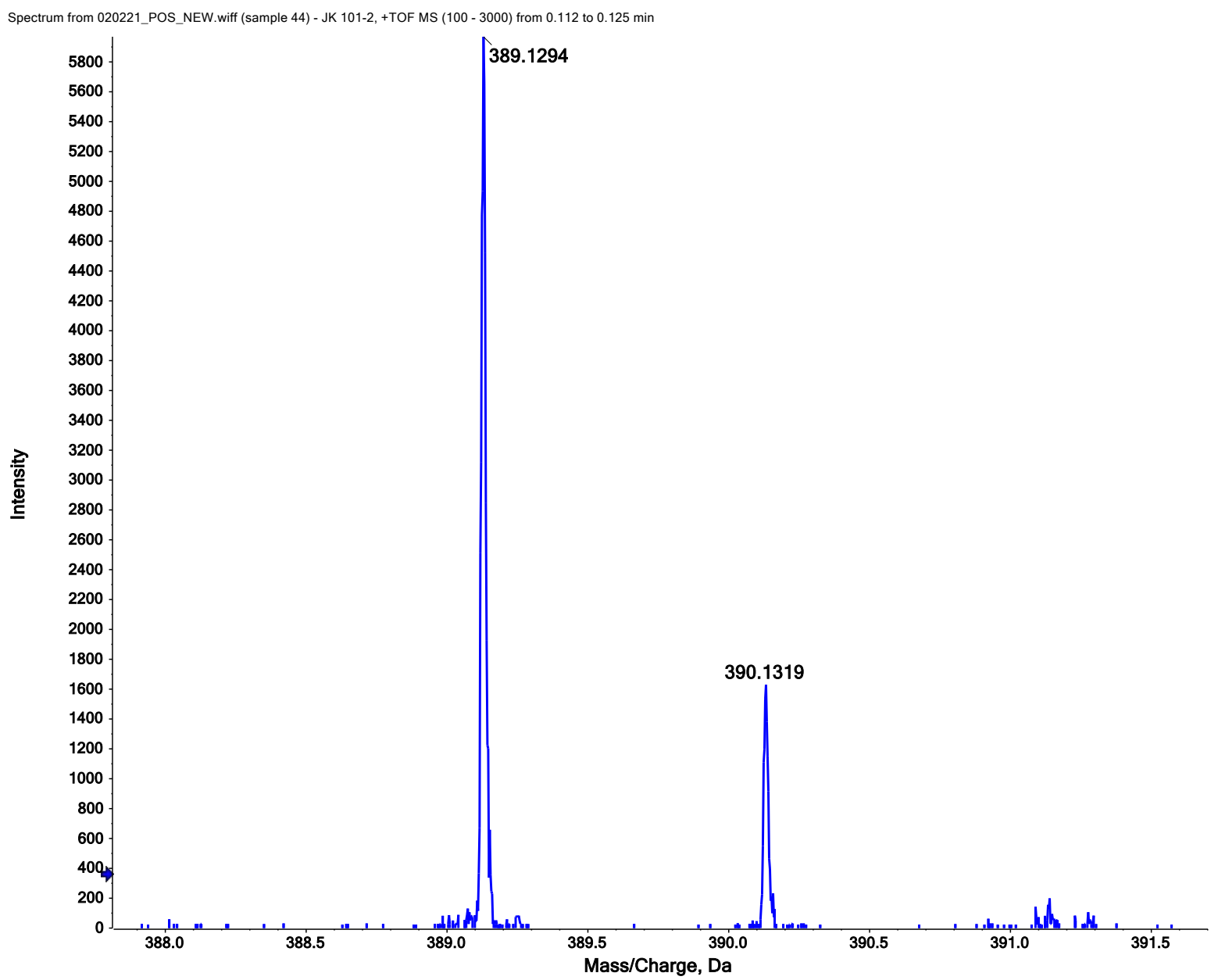

Figure S45. HRMS spectrum of compound trans-3n 


\section{2',4-dione (cis-3o)}
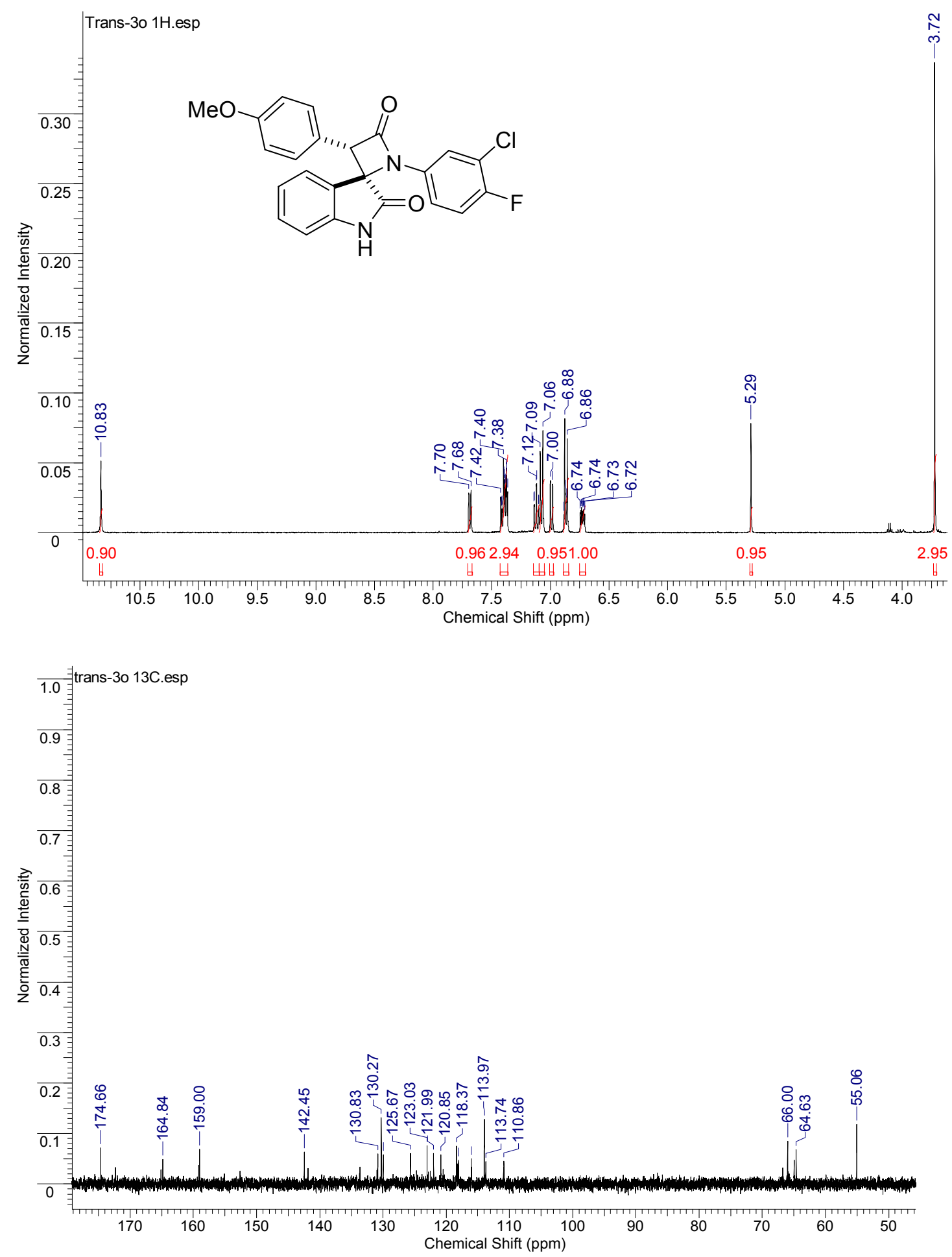

Figure S46. ${ }^{1} \mathrm{H}$ and ${ }^{13} \mathrm{C}$ NMR spectra of compound cis-3o 


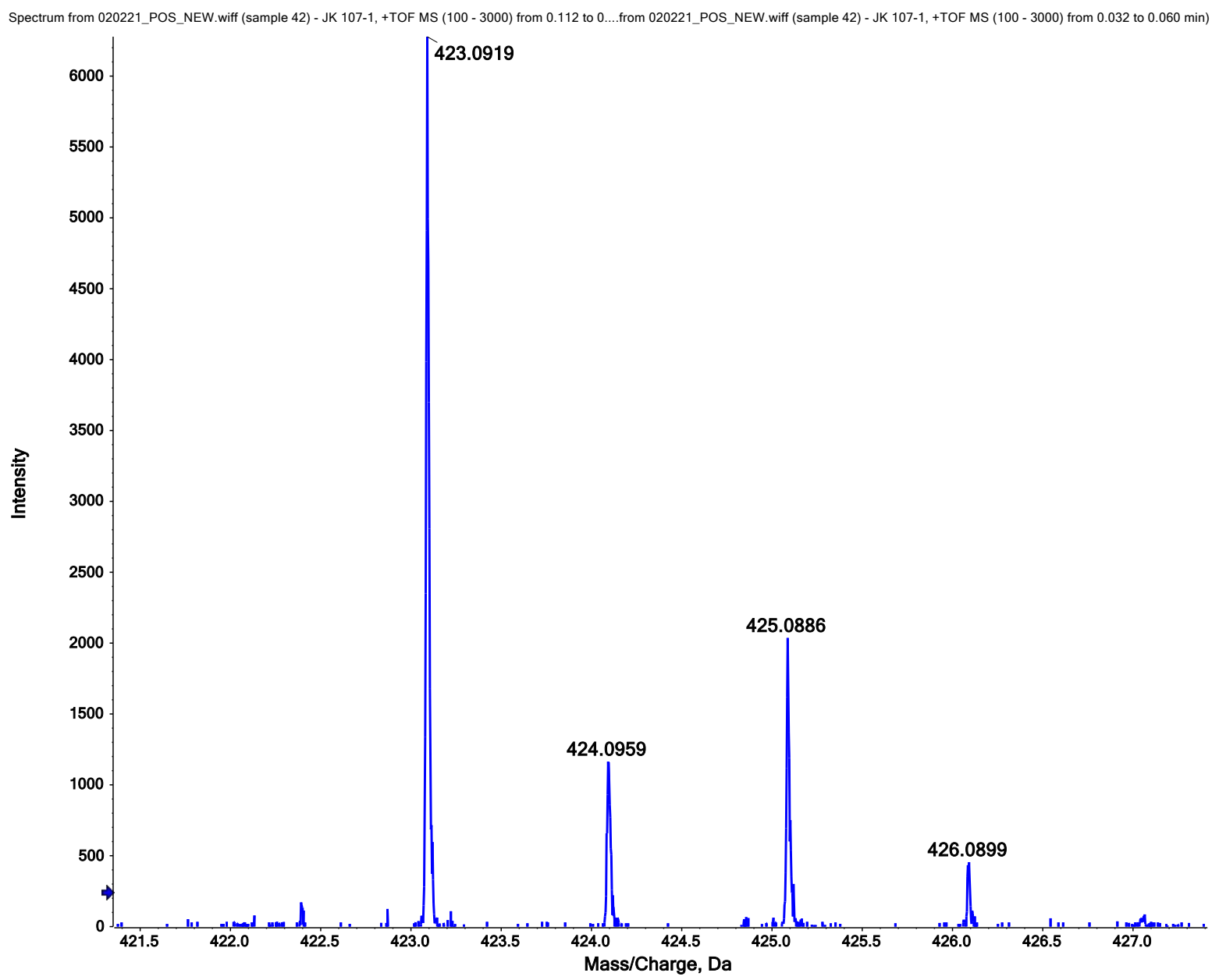

Figure S47. HRMS spectrum of compound cis-3o 


\section{2',4-dione (trans-3o)}
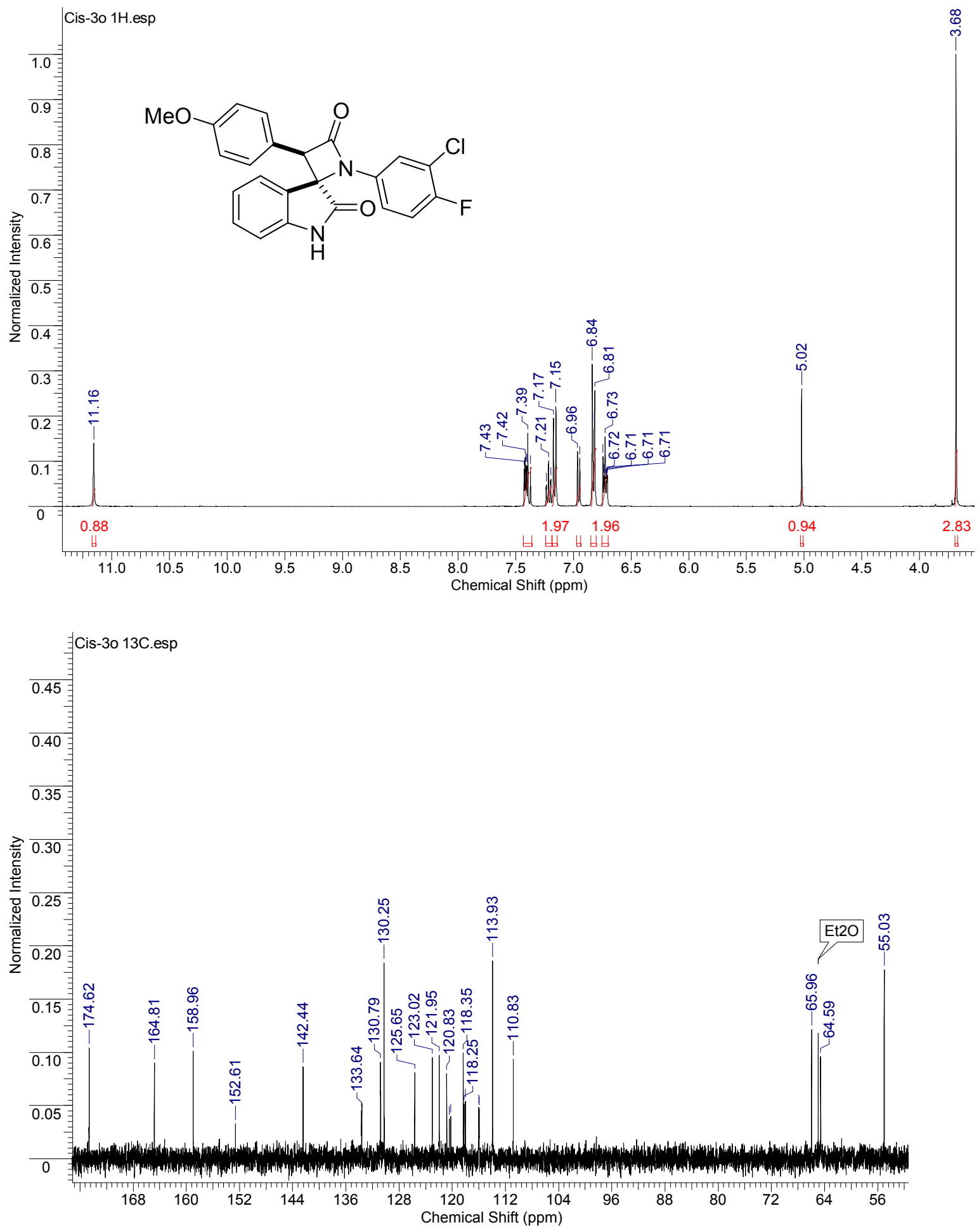

Figure S48. ${ }^{1} \mathrm{H}$ and ${ }^{13} \mathrm{C}$ NMR spectra of compound trans-3o 


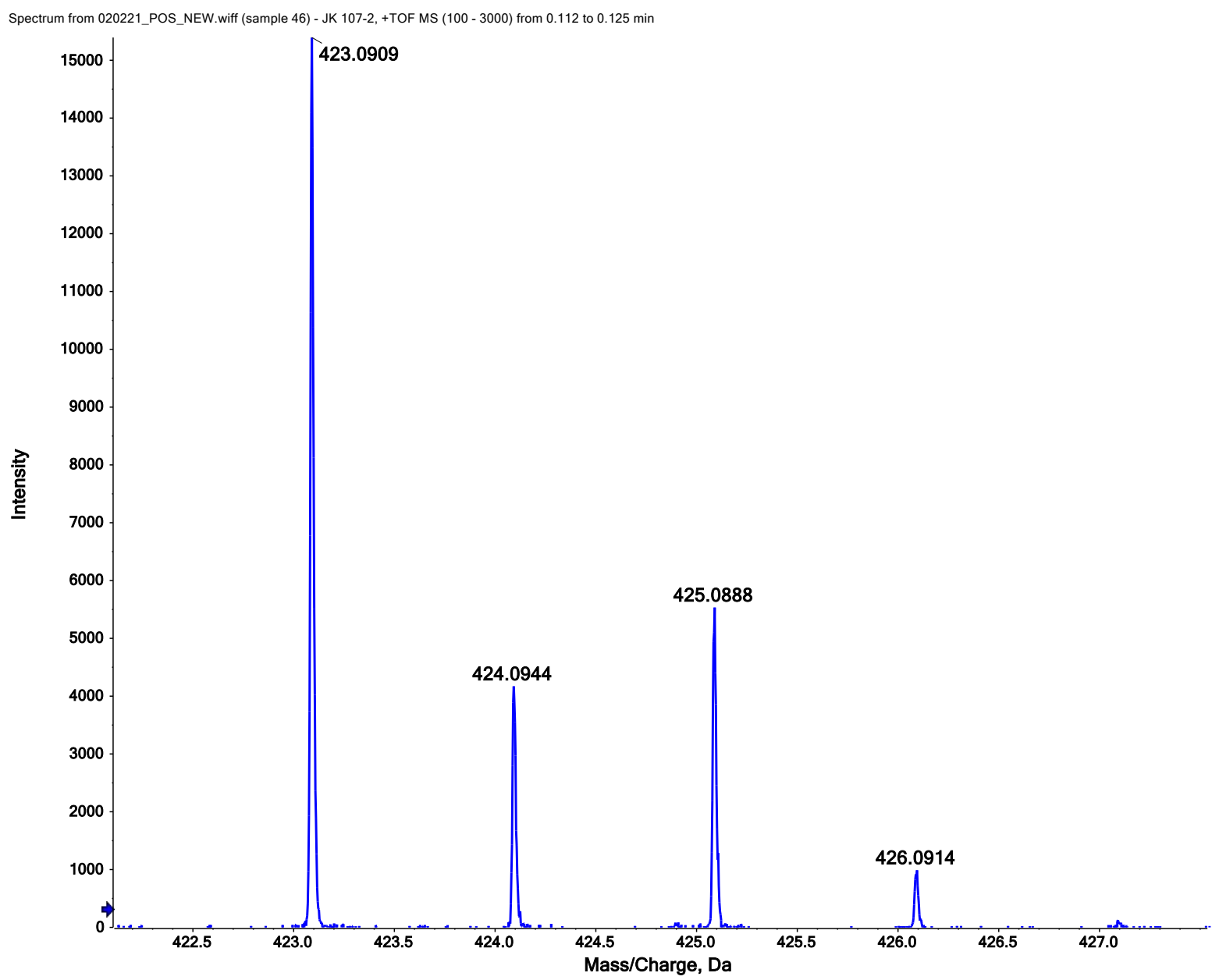

Figure S49. HRMS spectrum of compound trans-3o 
(trans-3p)
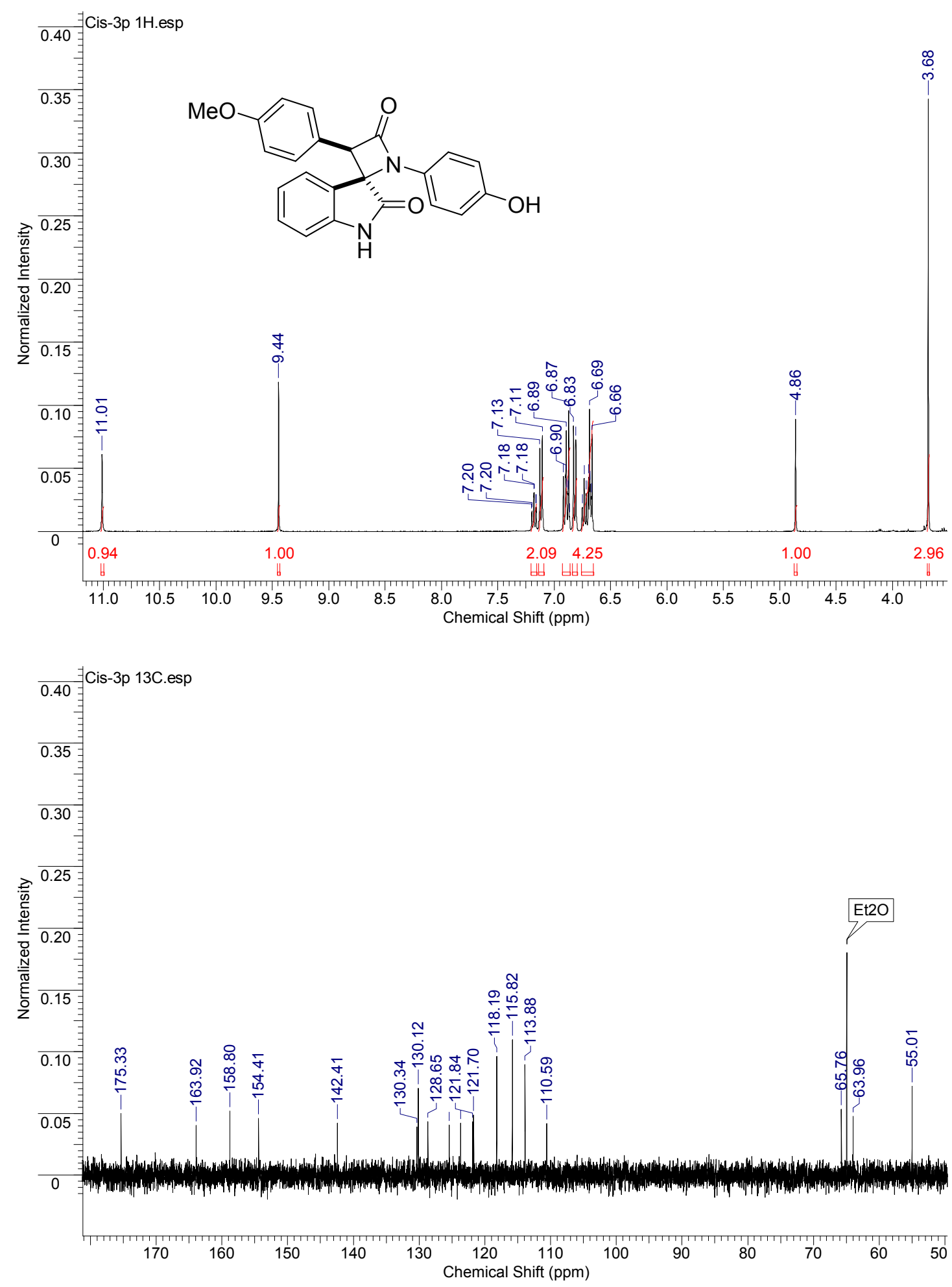

Figure S50. ${ }^{1} \mathrm{H}$ and ${ }^{13} \mathrm{C}$ NMR spectra of compound trans-3p 


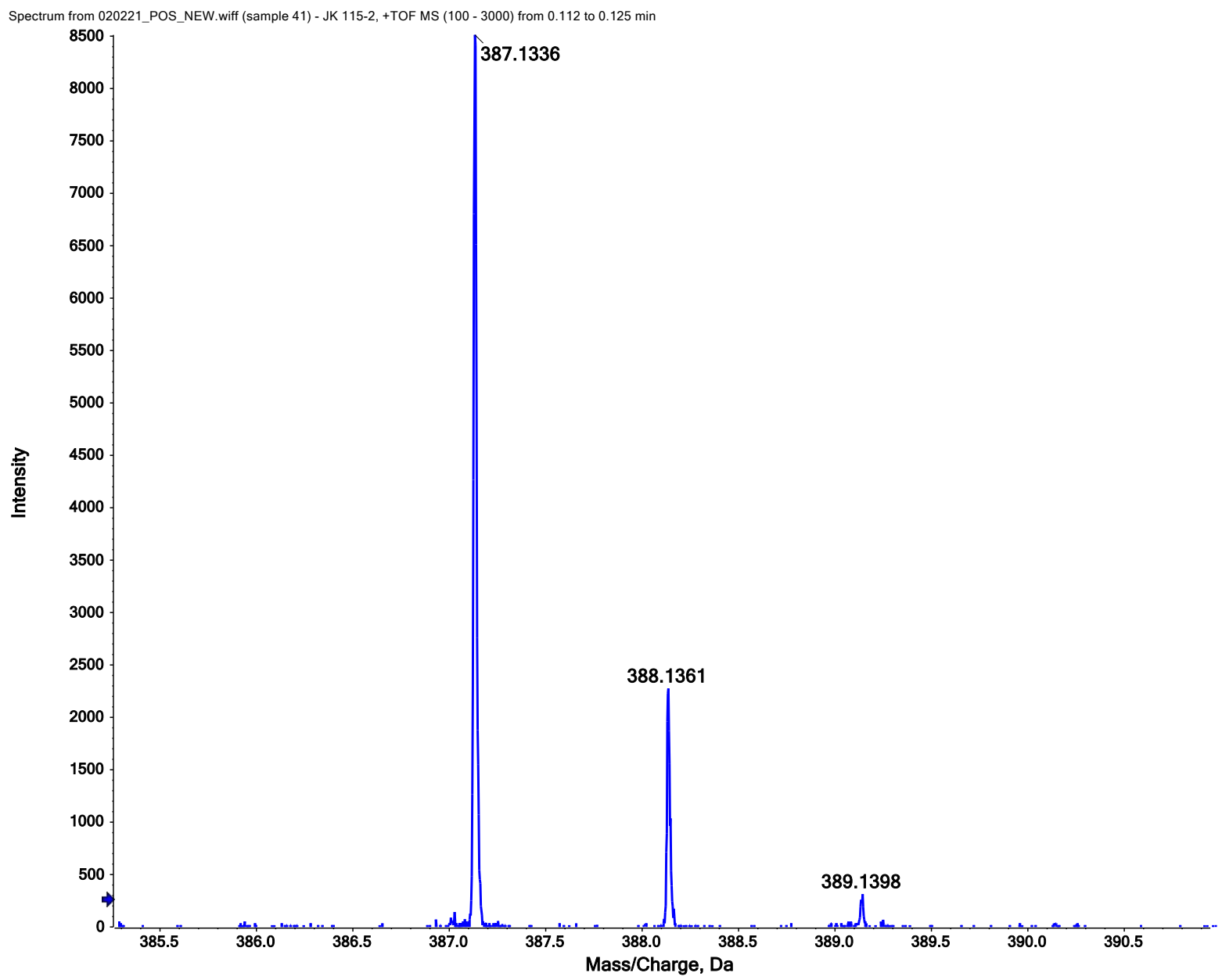

Figure S51. HRMS spectrum of compound trans-3p 


\section{X-Ray}

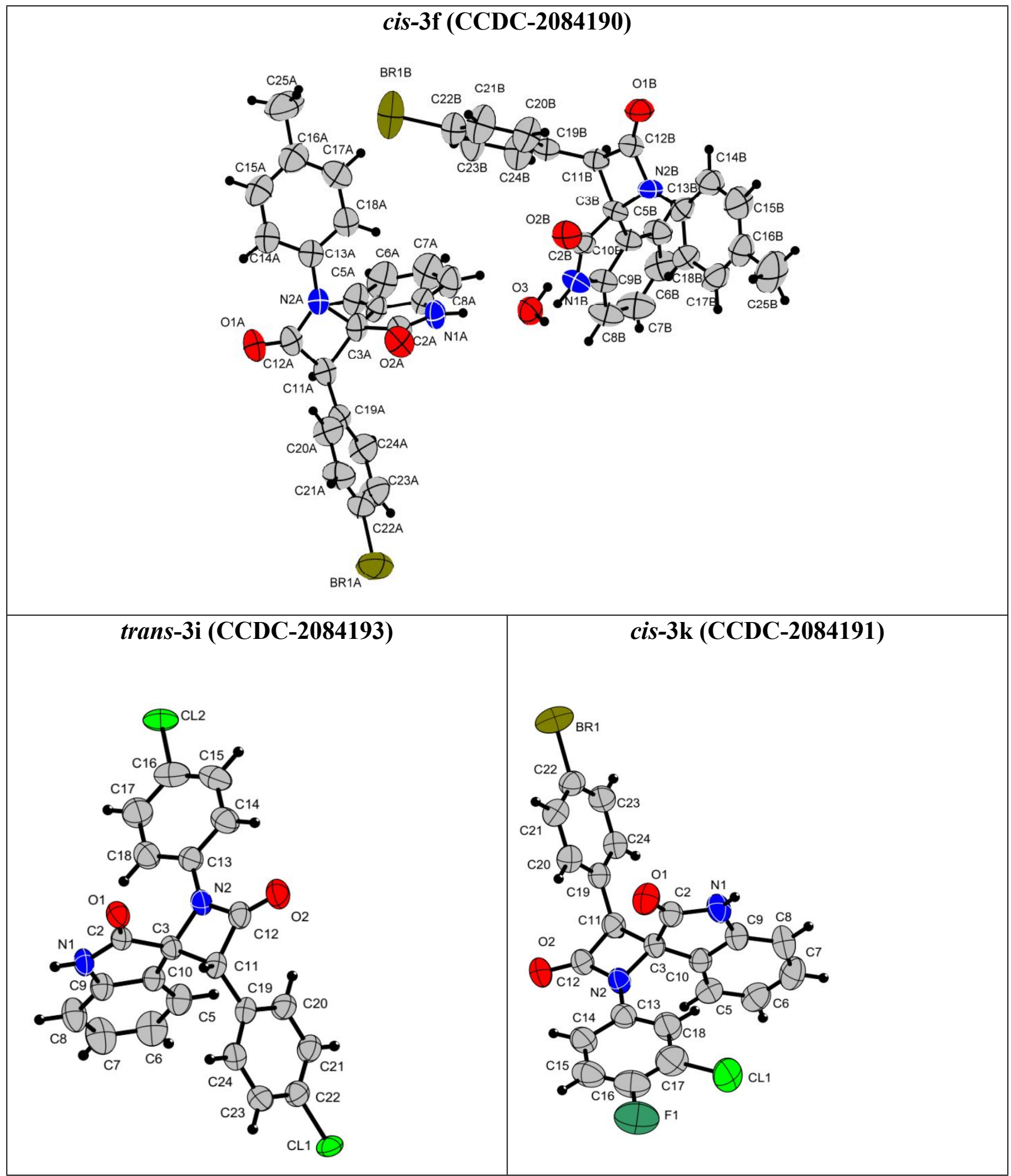

Figure S52. Molecular structures of compounds cis-3f, trans-3i, cis-3k 